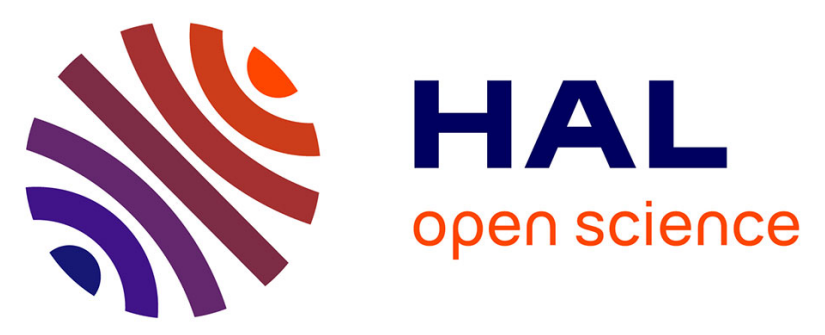

\title{
Experiments and nonlinear homogenization sustaining mean-field theories for refractory mortarless masonry: The classical secant procedure and its improved variants
}

\author{
Amna Rekik, Samir Allaoui, Alain Gasser, Eric Blond, Kirill Andreev, Sido \\ Sinnema
}

\section{To cite this version:}

Amna Rekik, Samir Allaoui, Alain Gasser, Eric Blond, Kirill Andreev, et al.. Experiments and nonlinear homogenization sustaining mean-field theories for refractory mortarless masonry: The classical secant procedure and its improved variants. European Journal of Mechanics - A/Solids, 2015, 49, pp.67-81. hal-01059712

\section{HAL Id: hal-01059712 \\ https://hal.science/hal-01059712}

Submitted on 1 Sep 2014

HAL is a multi-disciplinary open access archive for the deposit and dissemination of scientific research documents, whether they are published or not. The documents may come from teaching and research institutions in France or abroad, or from public or private research centers.
L'archive ouverte pluridisciplinaire HAL, est destinée au dépôt et à la diffusion de documents scientifiques de niveau recherche, publiés ou non, émanant des établissements d'enseignement et de recherche français ou étrangers, des laboratoires publics ou privés. 


\title{
Experiments and nonlinear homogenization sustaining mean-field theories for refractory mortarless masonry: the classical secant procedure and its improved variants
}

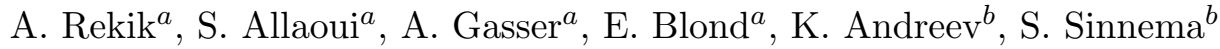 \\ ${ }^{a}$ Univ. Orléans, INSA-CVL, PRISME, EA4229, F45072 Orléans, France \\ ${ }^{b}$ Ceramics Research Center, Tata Steel RED, PO Box 10000, 1970CA Ijmuiden, The Netherlands
}

\begin{abstract}
In order to support the optimization of mortarless brick linings of steel producing furnaces it is proposed in this paper to investigate only the compressibility of dry refractory joints. To this end, optical measurements based on the Digital Image Correlation method were carried out during compression of Magnesia-Carbon brick samples with dry joints. The second main objective is to assess the accuracy of the secant linearization schemes (the classical secant procedure and its modified extension) to reproduce the reference local and global behaviour of refractory mortarless linings accounting for the identified inelastic convex power-law behaviour of the Magnesia-Carbon dry joint. The reference nonlinear solution is obtained by means of finite elements method. Under normal compressive loading, unlike for usual (concave) power-law viscoplastic composites for which the secant schemes are known to provide too stiff results, it was found that the modified secant scheme leads to good overall predictions. The classical secant procedure underestimates the reference local and overall behaviour. To improve the latter result, an empirical improved secant formulation was proposed and implemented. It leads to better estimates at local and global levels.
\end{abstract}

Key words: Mortarless joint; Digital Image Correlation; Nonlinear (convex) power-law behaviour; Linearization; Classical secant procedure; Modified secant method; improved empirical secant scheme; Homogenization

\section{Introduction}

Many large-sized structures as civil engineering or historical buildings, monumental structures and refractory ceramic linings of metallurgical vessels are made of masonry material. Masonry is a composite material obtained by joining natural (clay, stone, etc) or artificial (ceramic) bricks by means of mortar layers as in refractory linings. For reasons of durability and resistances to harmful factors (fire, water, chemical products, etc.), the conventional bonded masonry is replaced by mortarless masonry systems such as interlocking mortarless hollow concrete block systems [39], dry-stack mortarless sawn stone constructions (as the Egyptian pyramids and the Zimbabwe ruins for example) [37] and refractory linings of industrial furnaces including vessels of steel industry where the ceramic bricks are laid in direct contact with each other $[1,11,26]$.

For conventional mortared masonry structures, several approaches and models have been developed and presented in the literature to investigate and predict their behaviours. For numerical purpose, two main approaches have been adopted for mortared masonry modelling: macro-modelling and 
micro-modelling. For the global structural behaviour, the macro-modelling approach $[9,17,22]$ intentionally ignores the interaction between units and mortar but smears the effect of joint presence through the establishment of a relation between average strains and average stresses. It defines then a fictious homogeneous and continuous material equivalent to the studied masonry composite which is heterogeneous and discrete. Macro-approaches obviously require a preliminary mechanical characterization of the model based on experimental laboratory or in-situ tests on sufficiently large-sized masonry structures under homogeneous states of stress. The alternative micro-modelling approach adopted by many researchers $[13,18,19,20,29,34]$ is suitable for small structural elements with particular interest in strongly heterogeneous states of stress and strain. Its primary aim is to closely represent masonry from the knowledge of the properties of each constituent and the interface. The experimental data must be obtained from laboratory tests on masonry constituents and small masonry specimens. In studies based on micro analysis, two main approaches have been used: the simplified approach which is the more refined and the detailed micro-modelling approach. Simplified methods consist in modelling the bricks, mortar and interface separately by adopting suitable constitutive laws for each component. A simplified micro-model is an intermediate approach where the properties of the mortar and the mortar interface units are lumped into a common element, while expanded elements are used to model the brick units. Although this model reduces the computational cost of the analysis, some accuracy is obviously lost. Even it is proved that the micro-modelling approach gives highly accurate results especially at local level, such approach can hardly be used in practice for structural design since its model requires a separate discretization of bricks and joints, leads to intractable numerical difficulties as the size of the problem increases.

For mortarless masonry, there have been limited analytical and numerical studies which depend mainly on the type of blocks used to assemble the walls. Among these studies, a finite element model was proposed by Oh [27] to simulate the behaviour of interlocking mortarless block developed in Drexel University. Such a procedure is useful to simulate the contact behaviour of mortarless joint including geometric imperfection of the mortarless joint but is suitable only for modelling small masonry assemblies. Material nonlinearity is not considered to account for the behaviour of the masonry near the ultimate load and to predict failure mechanism. Alpa et al. [2] suggested a macro-model based on homogenization techniques to model the joint and the block as a homogenous material. That model focuses on the joint movement mechanism assuming perfect joint. This model ignores significant issues such as material nonlinearity, joint imperfection and progressive material failure. Recently, Thanoon et al. [39, 40] proposed a finite element model and developed an incremental-iterative program to predict the behaviour and failure mechanism of the system under compression. The nonlinear progressive contact behaviour of mortarless joint that takes into account the geometric imperfection of the block bed interfaces is included based on experimental testing. The developed contact relations for dry joint within specified bounds can be used for any mortarless masonry system efficiently with less computational effort. As a continuity of the work of Gasser et al. [11], Nguyen et al. [26] proposed a model based on linear homogenization technique performed with finite element method. It derived four equivalent homogeneous materials for which mechanical properties depend on the joint state, on the basis of the joint opening/closure mechanism. The transition criteria between these joint states are based on the unilateral contact conditions written in terms of macroscopic strain. Similar studies $[6,10]$ based on the same idea of four equivalent homogeneous materials for which mechanical properties depend on the joint state were carried on masonry refractory structures. On the other hand, Senthivel and Lourenço [37] developed a nonlinear finite element analysis based on experimental data to model deformation characteristics such as load-displacement envelope diagrams and failure modes of dry stack masonry shear walls subjected to combined axial compression and lateral shear loading. This analysis is 
based on a multi-surface interface model where bricks and joints are assumed elastic and inelastic, respectively. More recently, K. Andreev et al. [1] investigate the compressive closure of dry joints in two classes of refractory bricks: Magnesia-Carbon and Magnesia-Chromite bricks. The general aim of the investigation was to obtain data on the compressive joint closure behaviour to get a better insight into the masonry stress state and the joint condition during the service cycle of the furnace. To this end, the process of joint closure was measured indirectly by compressing samples with and without joints in wide temperature range. At room temperature, also direct optical measurements were performed. FEM computer analysis was used to interpret the measurement results.

Either for conventional mortared or mortarless masonry structures, a continuum model based on micromechanical considerations seems more preferable. Indeed, recently, especially in the case of regular masonry, efficient and reliable models based on periodic homogenization have been made to allow nonlinear analysis of large scale structures at a low numerical cost. The present work is closely connected with the latter kind of analysis. Its relevance is based on its dependence on nonlinear homogenization methods sustaining mean-field theories classically applied to nonlinear composites. In this paper, it is then proposed to assess the accuracy of predictive schemes belonging to the class of secant methods (the classical $[3,15]$ and its modified approach $[31,35,36]$ ) to the particular case of refractory mortarless masonry. At room temperature, the nonlinear behaviour of the mortarless ceramic joint was identified experimentally based on Digital Image Correlation (DIC) method. The behaviour of the brick unit was assumed to be linear elastic. Linearization procedures defining a linear comparison composite (LCC) were then applied only for the head and bed dry joint behaviours. The linear homogenization of the LCC's behaviour was performed using finite element method (FEM). Therefore, the approximations on the macroscopic level are related to the sole linearization procedure. Results of nonlinear homogenization sustaining mean-field theories are compared at global and local scales to the results of the nonlinear reference solution. Furthermore, it is proposed to improve the results of the classical secant scheme in order to better estimate local and global behaviours of mortarless masonry. Note that the methodology proposed in this paper can be enlarged to the more general case of mortared masonry or eventually for masonry at high temperatures.

\section{Experimental characterization of mortarless joint behaviour}

In many furnaces, e.g. converters of steel industry, Magnesia-Carbon (MaC) bricks are laid on dry joint, without usage of mortar. The quantitative knowledge of the compressive behaviour of dry joints is an essential design parameter. As an example one can regard the superposition of the stress reducing effect of the joint. For these reasons and in order to support optimization of refractory masonry structures only the compressibility of dry joint will be investigated. Compressive tests on a stack of two Magnesia-Carbon (MaC) bricks (without mortar) were carried out. Commercially available MaC bricks were used. Their composition is shown in Table 1. Because of their high resistance against chemical and mechanical wear the bricks are used in the insulating linings of steel making vessels. The morphology of the brick is bigger grains of Magnesia and graphite in the matrix of small Magnesia grains. The maximal grain size is $5 \mathrm{~mm}$. The bricks are resin bonded.

Tests were performed at atmospheric conditions on mechanical frame Instron 4507 with a load cell of $200 k N$ (Fig. (1)). The load accuracy is about $0.2 \%$ of the reached load. The samples are cut from bricks to dimensions of $100 \times 50 \times 50 \mathrm{~mm}^{3}$ and the faces are not polished. The compression tests are performed with constant displacement rate of $0.033 \mathrm{~mm} / \mathrm{min}$. 2D Digital Image Correlation (DIC) $[38,41]$ is used to measure the compressive behaviour of the dry joint 


\begin{tabular}{l|c}
\hline Material Type & $\mathrm{MaC}$ \\
\hline Density, $g / \mathrm{cm}^{3}$ & 2.93 \\
Open porosity, \% & 10 \\
$\mathrm{MgO}, \%$ & 98 \\
$\mathrm{Cr}_{2} \mathrm{O}_{3}, \%$ & - \\
$\mathrm{CaO}, \%$ & 1 \\
$\mathrm{Fe}_{2} \mathrm{O}_{3}, \%$ & 0.5 \\
$\mathrm{Al}_{2} \mathrm{O}_{3}, \%$ & - \\
$\mathrm{SiO}_{2}, \%$ & 0.5 \\
Total C, \% & 14 \\
\hline
\end{tabular}

Table 1: Chemical composition and physical properties of $\mathrm{MaC}$ bricks [1]

with a 7D correlation software [42]. The DIC is an optical method based on grey value digital images. The plane surface of the specimen is observed by a CCD camera that has a resolution of $1380 \times 1024$ pixels in our case. Then, the images on the specimen surface, one before and others after deformation, are recorded, digitized and stored in a computer as digital images. These images are compared to detect displacements by searching a matched point from one image to another by means of a series of mathematical mapping and cross correlation functions. Once the location of this point in the deformed image is found, the local strain tensor can be determined from the spatial distribution of the displacement field for each image.

As it is almost impossible to find the matched point using a single pixel, an area with multiple pixel points is used to perform the matching process. This area usually called subset should contain several clear features but it is often a compromise between resolution and accuracy. As a general rule, larger subset sizes will increase the accuracy whereas a smaller subset will increase the resolution but realistically the size of a subset is determined by the quality of the image and speckle pattern. In our case, another criterion is added for the subset size. Indeed, in order to evaluate the joint behaviour, the grid must be put in place on the joint and must have only a small overlap onto the bricks. For that, the grid steps have been optimized before using the DIC analysis on joints. The chosen subset is $6 \times 6$ pixels that corresponds to an area width of about $0.5 \mathrm{~mm}$. The accuracy of the DIC reaches 0.01 pixel which represents in our case a resolution of $0.001 \mathrm{~mm}$ on the displacement. In order to perform this process, a grey scale random pattern that allows matching the subset is needed on the surface of the specimen. In our case, the natural pattern of the bricks is enough to produce a suitable pattern.

Due to roughness, shape defaults and non parallelism of faces, the dry joint is not horizontally aligned and its thickness is not constant. It is difficult to contain the joint in the same line of subsets. For this, measurements were performed at different locations along a joint (Fig. (2)). For each location, the DIC method allows the measurement of the evolutions of the local normal $\varepsilon_{n n}$, tangential $\varepsilon_{t t}$ and shear $\varepsilon_{n t}$ strains. These strain components were averaged over each grid area and lead to the dry joint compressive stress-strain curves as shown on Fig. (3)-a for the third selected area for example.

Note that the DIC method does not provide the local stress in the dry joint. Moreover, as the bricks and dry joint are disposed in series, it is possible to assume that $\boldsymbol{\sigma}(x)$ is set equal to the imposed normal stress $\bar{\sigma}_{n n} \boldsymbol{n} \otimes \boldsymbol{n}$. On Fig. (3)-a, it can be seen that at the beginning, intensive joint strain develops at relatively low stresses. With progressive loading, reaction to the compaction increases. At a certain stress level the joint appears to be closed completely as the closure curve aligns itself 


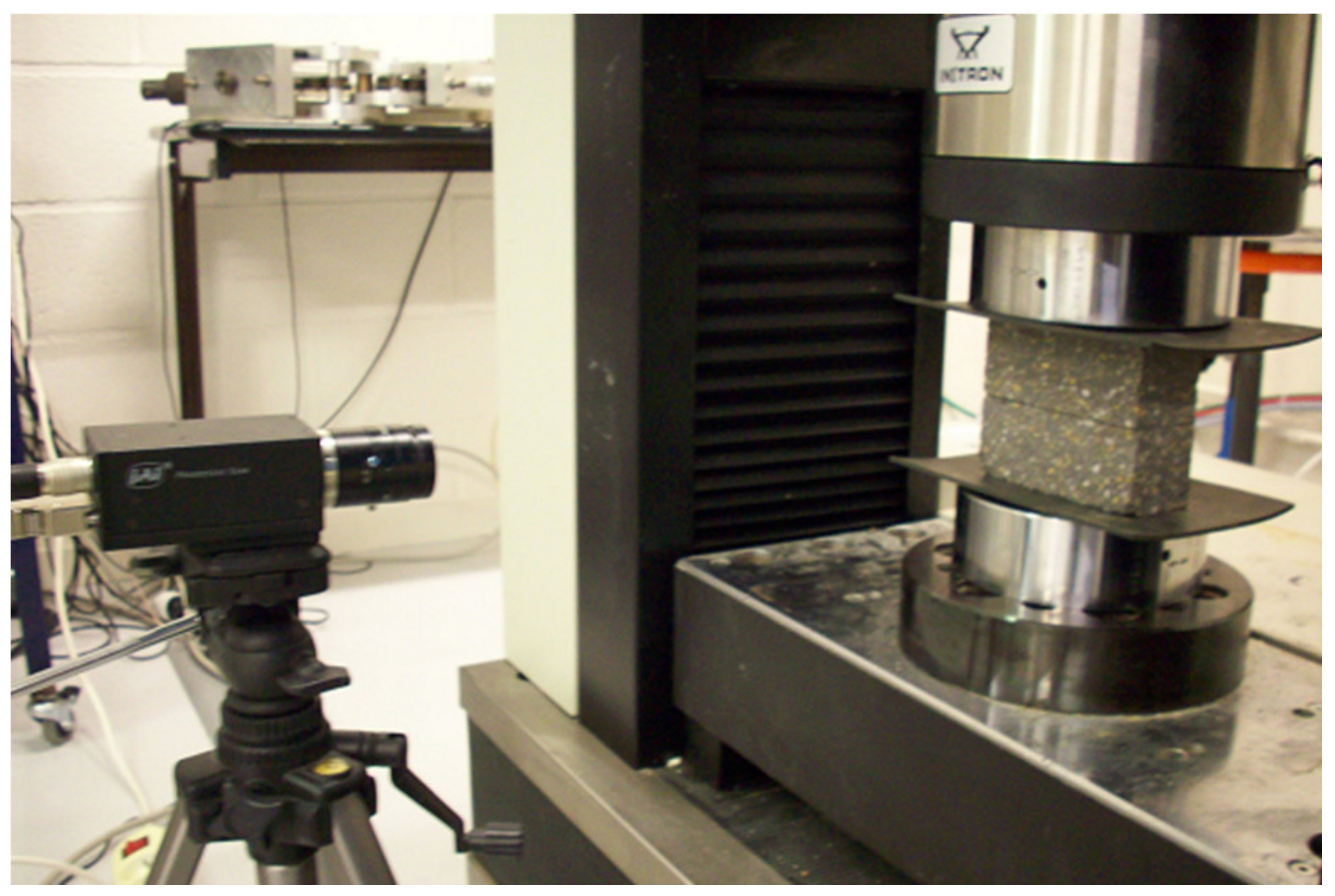

Figure 1: Experimental setup, compression test on brick-dry joint-brick laminate

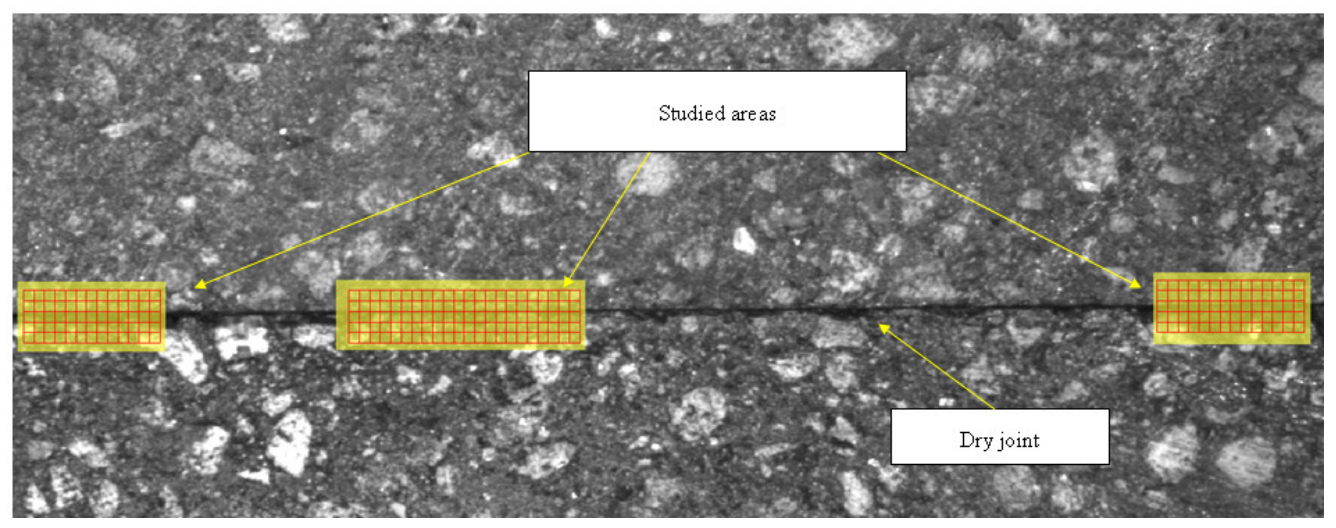

Figure 2: Optical measurement areas during a two brick compression test (MaC) 

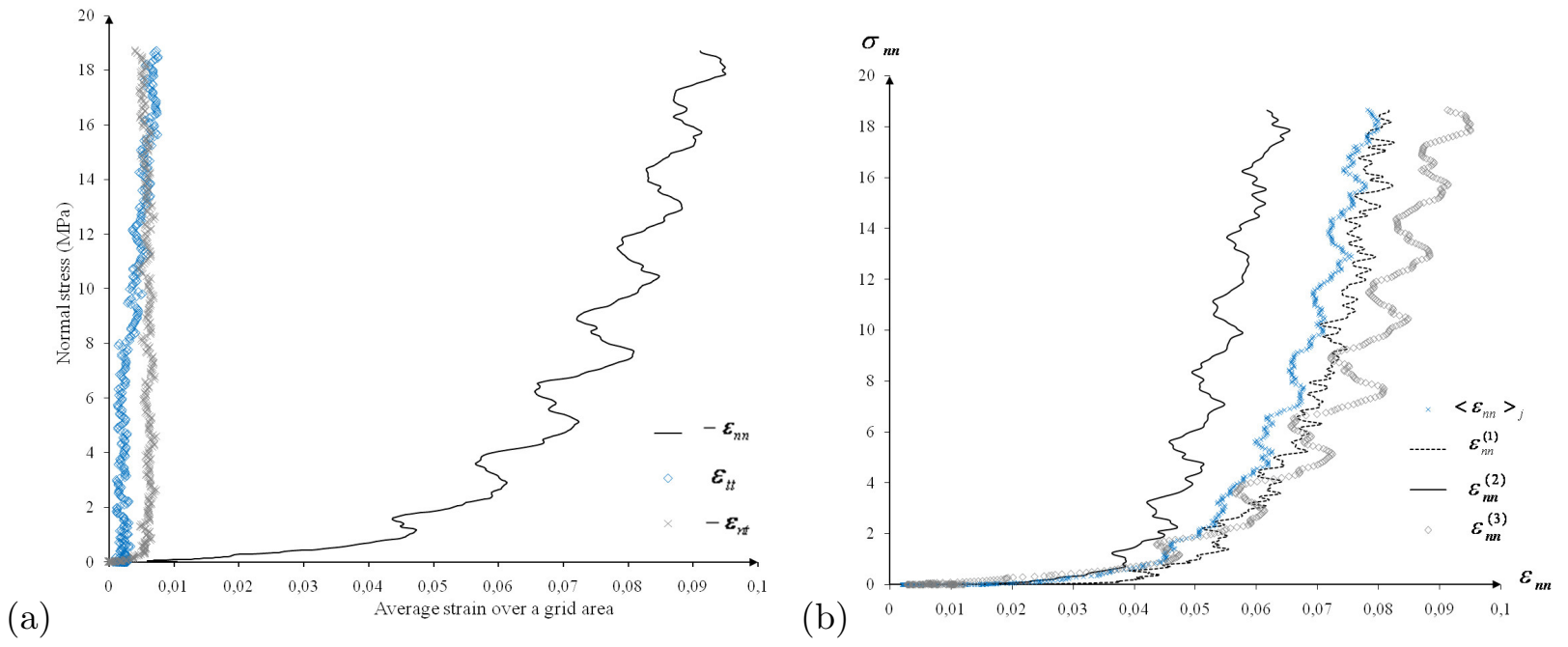

Figure 3: "Stress-strain components" curves (a) and " $\sigma_{n n}-\varepsilon_{n n}$ " evolutions at different areas selected around the mortarless joint of $\mathrm{MaC}$ material

parallel to the compressive stress axis. After the joint closure, the compressive behaviour of the sandwich brick/dry-joint/brick will be approximatively linear. Fig. (3)-b presents an example of measurements taken at different locations of a MaC dry joint. We note that the compressive strains are different according to the place where they were determined, but the dispersion remains correct. The fluctuation of the obtained data is due to the pattern size which is function of the microstructure size of the Magnesia-Carbon material. The bad contact resulting from natural roughness or from the fact that the contacting surfaces are not perfectly plan parallel is also a parameter that influences the fluctuation and the dispersion of the measured strains.

In the following, the subscripts $b$ and $j$ denote the bricks and joints, respectively. The properties of the dry joint are evaluated in terms of the average over all the selected areas $A_{i}(i=1, N)$ of the local normal stress and strain components $\varepsilon_{n n}, \varepsilon_{t t}, \varepsilon_{n t}$ and $\varepsilon_{z z}$. Indeed, the latter component is not null under the adopted assumption of plane stress. Moreover, the shear strain components $\varepsilon_{l z}(l=t$ or $\boldsymbol{n})$ are null and the strain components $\varepsilon_{t t}$ and $\varepsilon_{z z}$ are assumed to be equal in the $(\boldsymbol{t}$, $\boldsymbol{z})$ plane orthogonal to the direction of the compressive loading.

\section{Nonlinear homogenization of refractory mortarless linings}

Since refractory mortarless linings present periodic microstructure, it is possible to consider only a periodic cell as shown on Fig.(4)-a. Note that the MaC bricks are assumed to follow an isotropic linear elastic behaviour. That of the dry joints is nonlinear as identified previously by the DIC method. The lining's periodic microstructure enables a finite elements (FE) computation of the local and global responses. The FE result is regarded as reference solution and denoted hereafter by NL. Note that the local and overall behaviour of the mortarless masonry can also be estimated or approximated by means of nonlinear mean-field homogenization theories such as the classical secant procedure and its modified extension. Other "stress-strain" linearization schemes (e.g. the affine formulation) or potential-based approaches (the tangent second-order formulation, for instance) are to be adressed in the future since they need much more material parameters such as the polarization (or pre-stress) and the pre-strain for thermoelastic "stress-strain" formulations or the potential strain energy for "potential-based" approaches. 
For mortarless refractory linings, in order to assess the accuracy of the existing secant linearization schemes known to provide too stiff predictions for usual viscoplastic power-law composites (see for instance [33]), it is proposed to compare their predictions at global and local scales by reference to the NL solution. Moreover, in order to evaluate the sole effect of the linearization scheme without any bias or ambiguity, it is proposed to avoid any approximation related to the linear homogenization step. The main idea relies on the adoption of an LCC with an identical microstructure to that of the original problem and to perform FE linear homogenization on this LCC by means of finite elements method. Besides, as the periodic cell presents two axes of symmetry: the normal and the tangential directions along the unit vectors $\boldsymbol{n}$ and $\boldsymbol{t}$, respectively, only its quarter (see Fig. (4)-b) will be retained for computation. In this paper note that the term "exact" is let between quotation

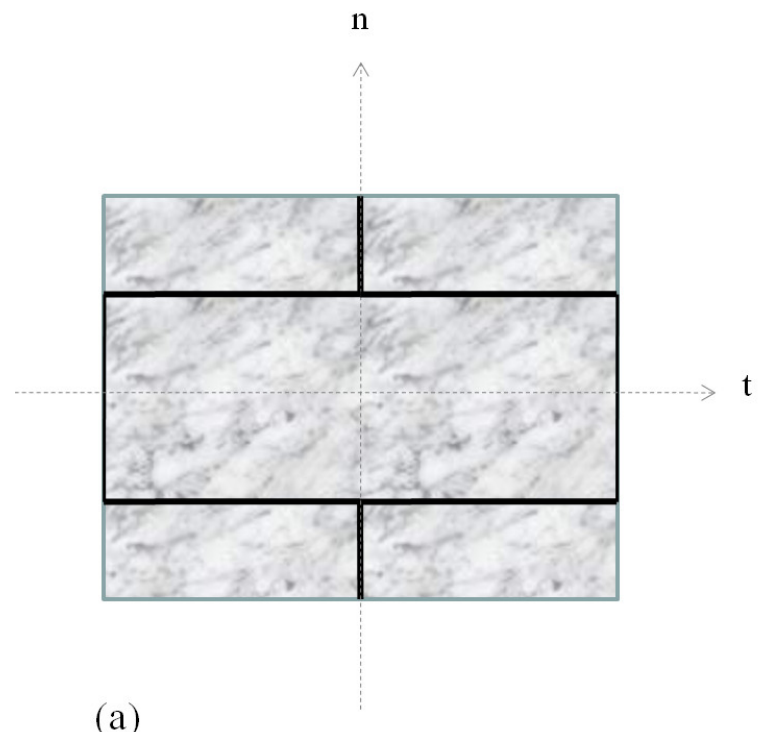

(a)

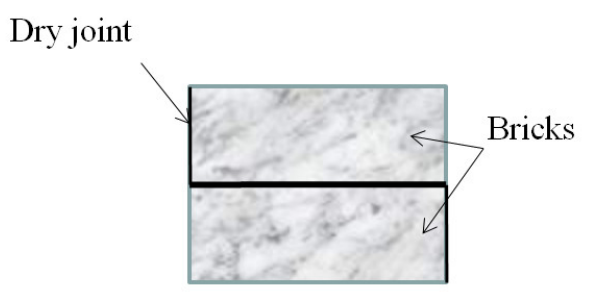

(b)

Figure 4: Periodic masonry cell (a) and its quarter part (b) considered for the modelling.

marks since the accuracy of the reference solution depends on the numerical errors and mainly on the accuracy of the adopted functions fitting the experimental data.

\subsection{Reference solution: FE nonlinear homogenization}

\subsubsection{Reference material properties of the constituents}

The following power-law relation between the local normal stress $\sigma_{n n}$ and normal strain $\varepsilon_{n n}$ is identified using the experimental data for the MaC mortarless joint (see Figure (5)):

$$
\sigma_{n n}\left(\varepsilon_{n n}\right)=E_{e}^{j} \varepsilon_{n n}+\sigma_{0} \varepsilon_{n n}^{m_{0}}
$$

where the scalars $E_{e}^{j}, \sigma_{0}(\mathrm{MPa})$ and $m_{0}$ are given in Tab. (2). Note that the scalar $E_{e}^{j}$ can be

\begin{tabular}{ccc}
\hline$E_{e}^{j}$ & $\sigma_{0}$ & $m_{0}$ \\
\hline 0.489 & $2.1110^{6}$ & 4.6 \\
\hline
\end{tabular}

Table 2: Parameters of the "normal stress- normal strain" relation for the MaC mortarless joint. 


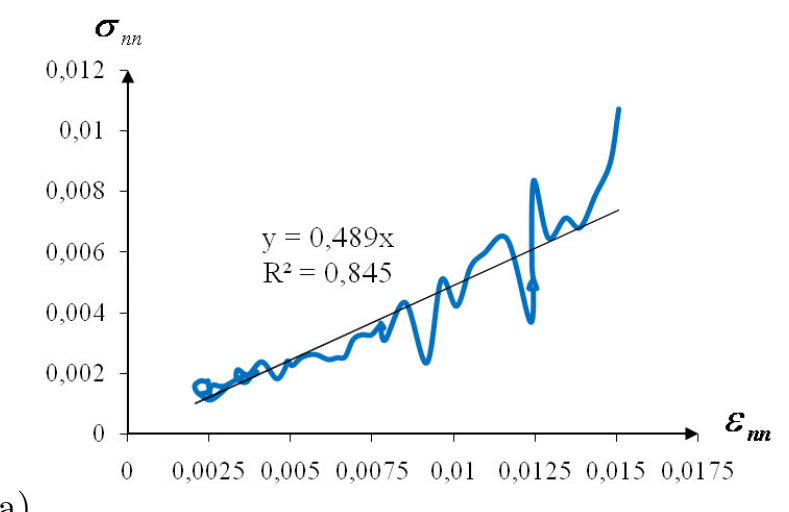

(a)

(b)

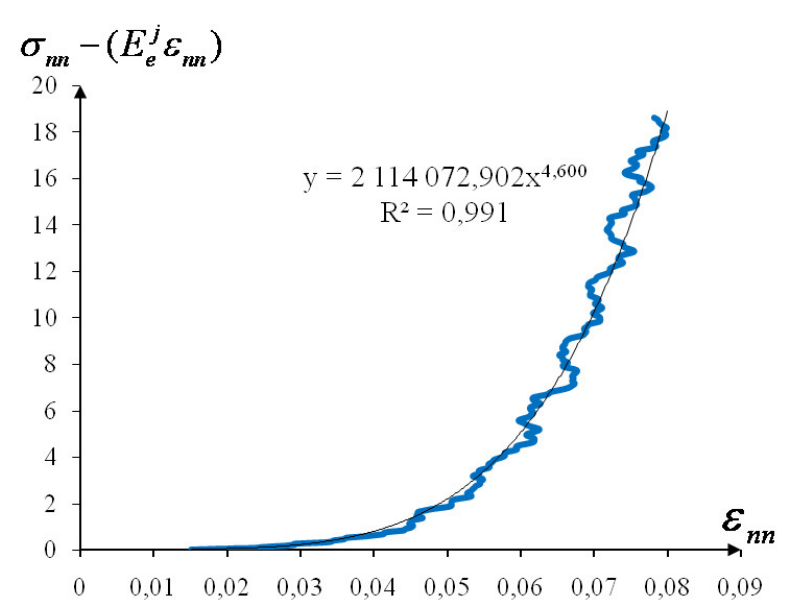

Figure 5: Evolutions of the experimental data: the linear part of the MaC mortarless joint's " $\sigma_{n n^{-}} \varepsilon_{n n}$ " relation (a) and " $\left(\sigma_{n n}-\left(E_{e}^{j} \varepsilon_{n n}\right)\right)-\varepsilon_{n n}$ " evolution (b) functions of the local normal strain $\varepsilon_{n n}$.

considered as the initial Young's modulus of the interphase since it is determined by the linear part of the curves " $\sigma_{n n}-\varepsilon_{n n}$ " (see Figure (5)-a). Moreover, by analogy with the usual (concave) powerlaw viscoplastic materials, the constant $\sigma_{0}$ can be assumed to represent the flow stress parameter. Note that, in the current study, the exponent $m_{0}$ is superior to 1 which is not the case for the usual viscoplastic (concave) power-law composites for which it is well known that the work-hardening exponent $m$ is less than 1 . This is due to the convex qualitative trend of the " $\sigma_{n n}-\varepsilon_{n n}$ " constitutive law.

The local normal compressive behaviour of the dry joint can then be defined by the nonlinear convex power-law " $<\sigma_{n n}>^{j}-<\varepsilon_{n n}>^{j}$ " relationship given by equation (1). However, the transversal behaviour of the considered interphase can be defined by the evolution of the ratio $-\frac{\left\langle\varepsilon_{t t}\right\rangle^{j}}{\left\langle\varepsilon_{n n}\right\rangle^{j}}$ between the tangential and normal strain field components over the interphase, denoted hereafter by the parameter $\nu^{j}$, as a function of the interphase local normal strain $\varepsilon_{n n}$. This evolution depicted on Fig. (6)-a can be fitted by the ensuing polynomial second-order evolution

$$
\nu^{j}\left(\varepsilon_{n n}\right)=c_{2} \varepsilon_{n n}^{2}+c_{1} \varepsilon_{n n}+c_{0}
$$

The scalars $c_{i}(i=0,2)$ are given by Table (3). A linear approximation of the evolution of " $\nu^{j}-\varepsilon_{n n}$ "

\begin{tabular}{ccc}
\hline$c_{2}$ & $c_{1}$ & $c_{0}$ \\
\hline 29.16 & -3.313 & 0.131 \\
\hline
\end{tabular}

Table 3: Parameters of the evolution law of $\nu^{j}$ as function of the MaC mortarless joint's local normal strain.

was avoided because it presents more than one slope (two different slopes) and the accuracy for each linear approximation is less than 0.5 shown on Fig. (6)-a. Moreover, since this evolution (see Fig. (6)-a) is very fluctuant, a polynomial approximation of the parameter $\nu^{j}$ with a degree greater than 2 was also avoided. Indeed, in practice, such polynomial approximation does not necessarily improve the accuracy shown on Fig (6)-a - either inferior or not much higher (around 0.6 instead of 0.5 for e.g. for a polynomial function of degree 3 or 4 ). For the isotropic linear elastic behaviour of the MaC bricks, the Young's modulus and Poisson's ratio are taken respectively set equal to $E^{b}=10 \mathrm{GPa}$ and $\nu^{b}=0.1$ (see $\left.[1]\right)$. 

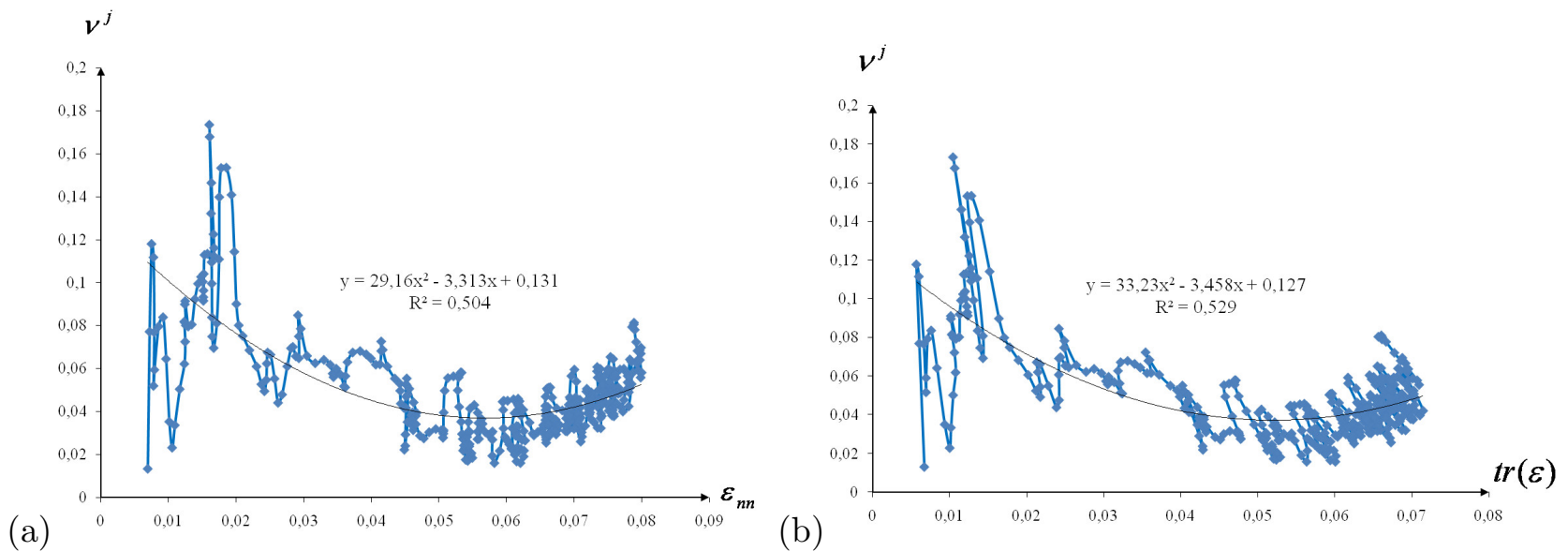

Figure 6: Evolution of the dry joint's parameter $\nu^{j}$ as function of (a) the local normal strain $\varepsilon_{n n}$ and (b) the spherical part $\operatorname{tr}(\varepsilon)$ of the local strain.

\subsubsection{Reference local and global behaviours of the nonlinear mortarless masonry}

For the considered nonlinear problem, the local stress $\boldsymbol{\sigma}$ and strain $\varepsilon$ fields in the periodic unit cell, assumed to have the volume $V$ and to be submitted to the macroscopic strain $\bar{\varepsilon}$, are solutions of the following set of equations [5]

$$
\left\{\begin{array}{l}
u(x)=\bar{\varepsilon} \cdot x+u^{*}(x), \forall x \in V \text { and } u^{*} \# \text { on } \partial V \\
\left.\varepsilon(u(x))=\frac{1}{2}\left(\nabla u(x)+^{t} \nabla u(x)\right)=\bar{\varepsilon}+\varepsilon\left(u^{*}(x)\right)\right), \forall x \in V \\
\operatorname{div}(\boldsymbol{\sigma})=0, \forall x \in V \text { and } \boldsymbol{\sigma} \cdot n-\# \text { on } \partial V \\
\boldsymbol{\sigma}(x)=\sum_{r=j, b} \chi^{r}(x) g_{r}(\varepsilon(x)), \quad \forall x \in V
\end{array}\right.
$$

where $u$ is the local displacement vector and $u^{*}$ is its fluctuanting part. $\chi^{r}(x)$ is the characteristic function of phase $r$ (set to 1 if $x \in V^{r}$ and 0 otherwise) and $g_{r}$ is the nonlinear constitutive law $\boldsymbol{\sigma}=g_{r}(\boldsymbol{\varepsilon})$ followed by this phase. The general notations \# and - \# mean that the fluctuating part of the displacement vector $u^{*}$ and the surface compression $\boldsymbol{\sigma} . n$ ( $\boldsymbol{n}$ being the outer normal) are periodic and anti periodic on the cell boundary $\partial V$, respectively. Note that the average $\left\langle\varepsilon\left(u^{*}(x)\right)>_{V}\right.$ over the periodic unit cell of the strain field of the fluctuating part $u^{*}$ of the displacement vector is null $[25]$.

The local and effective behaviours of the mortarless refractory unit cell are computed using the software Cast3M [7] under the assumption of a plane stress field. In the unit periodic cell, the joints and bricks are assumed to be perfectly bonded. To determine the effective behaviour of the cell, three types of loading are applied to the periodic mortarless unit cell. Since the behaviour of the dry joint's can be assumed to be piecewise linear, it is possible to define at each strain increment the following macroscopic law $\overline{\boldsymbol{\sigma}}=\tilde{\boldsymbol{L}}: \overline{\boldsymbol{\varepsilon}}$ where $\overline{\boldsymbol{\sigma}}=\left\langle\boldsymbol{\sigma}>_{V}\right.$ is the overall stress over the periodic cell and $\tilde{\boldsymbol{L}}$ denotes the instantaneous "secant" reference effective stiffness of the mortarless refractory unit cell.

According to the classical Voigt notation, the constitutive behaviour law of the unit cell reads:

$$
\left(\begin{array}{c}
\bar{\sigma}_{n n} \\
\bar{\sigma}_{t t} \\
\bar{\sigma}_{n t}
\end{array}\right)=\left(\begin{array}{ccc}
\tilde{L}_{n n n n} & \tilde{L}_{n n t t} & 0 \\
\tilde{L}_{n n t t} & \tilde{L}_{t t t t} & 0 \\
0 & 0 & \tilde{L}_{n t n t}
\end{array}\right)\left(\begin{array}{c}
\bar{\varepsilon}_{n n} \\
\bar{\varepsilon}_{t t} \\
2 \bar{\varepsilon}_{n t}
\end{array}\right)
$$

where $\bar{\sigma}_{k l}=f_{j} \bar{\sigma}_{k l}^{j}+f_{b} \bar{\sigma}_{k l}^{b}, f_{r}$ is the volume fraction of the phase $r$ defined by $f_{r}=\frac{V^{r}}{V}$ and $\overline{\boldsymbol{a}}^{r}=\langle\boldsymbol{a}\rangle^{r}$ is the average over phase $r$ of the stress or strain field component $\boldsymbol{a}$. 
Note that the software Cast3M provides the reference local strain and stress fields inside each phase - the bricks and mortarless joints -. Moreover, it allows the calculation of the average fields over each phase. For computation purposes, note that the components $\varepsilon_{t t}$ and $\varepsilon_{z z}$ inside the dry joint are not assumed to be equal, as it is the case in the previous section, but they are given due to the finite elements method.

The relations between the components of the effective stiffness $\tilde{L}_{i j k l}$ and the overall elastic engineering constants (normal $\tilde{E}_{n}$ and tangential $\tilde{E}_{t}$ Young's modulus, Poisson's ratios $\tilde{\nu}_{n t}$ and $\tilde{\nu}_{t n}$, shear modulus $\tilde{G}_{n t}$ ) under plane stress assumption read:

$$
\left\{\begin{array}{l}
\tilde{L}_{n n n n}=\frac{\tilde{E}_{n}}{1-\tilde{\nu}_{n t} \tilde{\nu}_{t n}} \\
\tilde{L}_{t t t t}=\frac{\tilde{E}_{t}}{1-\tilde{\nu}_{n t} \tilde{\nu}_{t n}} \\
\tilde{L}_{n n t t}=\frac{\tilde{E}_{n} \tilde{\nu}_{t n}}{1-\tilde{\nu}_{n t} \tilde{\nu}_{t n}} \\
\tilde{L}_{n t n t}=\tilde{G}_{n t} \\
\frac{\tilde{\nu}_{n t}}{\tilde{E}_{n}}=\frac{\tilde{\nu}_{t n}}{\tilde{E}_{t}}
\end{array}\right.
$$

To assess the effective elastic engineering constants, it is proposed (as mentioned above) to subject the unit cell to three types of loading: compression along $\boldsymbol{t}$, compression along $\boldsymbol{n}$ and shear loading. In the following, as we have only experimental data related to the compressive behaviour of the $\mathrm{MaC}$ mortarless joint, we will consider only two types of loading as explained below. The case of shear loading is left for a future work.

Axial compression along $\boldsymbol{n}$.

The applied macroscopic strain reads:

$$
\bar{\varepsilon}=\bar{\varepsilon}_{n n} \boldsymbol{n} \otimes \boldsymbol{n}
$$

As shown on Figure (7-a), the upper face of the quarter periodic cell is submitted to an uniform normal displacement $u_{n}=\bar{\varepsilon}_{n n} l_{n}$, where $l_{n}$ represents the cell's height. As the software Cast3M allows to evaluate the average over the cell of the stress components $\sigma_{n n}$ and $\sigma_{t t}$ and according to the relation (4), it is possible to determine the effective stiffness components $\tilde{L}_{n n n n}$ and $\tilde{L}_{n n t t}$ as follows:

$$
\tilde{L}_{n n n n}=\frac{\bar{\sigma}_{n n}}{\bar{\varepsilon}_{n n}} \quad \text { and } \quad \tilde{L}_{n n t t}=\frac{\bar{\sigma}_{t t}}{\bar{\varepsilon}_{n n}}
$$

Axial compression along $\boldsymbol{t}$.

In order to determine the effective stiffness component $\tilde{L}_{t t t t}$, the macroscopic strain in this case reads:

$$
\bar{\varepsilon}=\bar{\varepsilon}_{t t} \boldsymbol{t} \otimes \boldsymbol{t}
$$

which corresponds to the uniform displacement: $u_{t}=\bar{\varepsilon}_{t t} l_{t}$ prescribed on the right face of the quarter cell (see Figure (7-b)). The length $l_{t}$ denotes the cell's width. According to the equations (4) and (8), the component $\tilde{L}_{t t t t}$ is given by:

$$
\tilde{L}_{t t t t}=\frac{\bar{\sigma}_{t t}}{\bar{\varepsilon}_{t t}}
$$




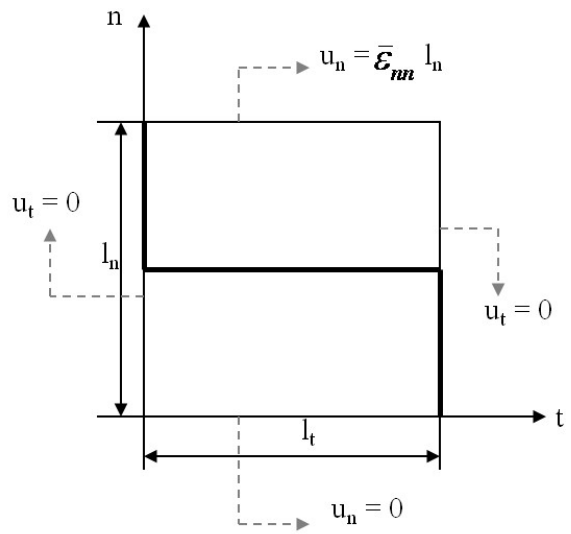

(a)

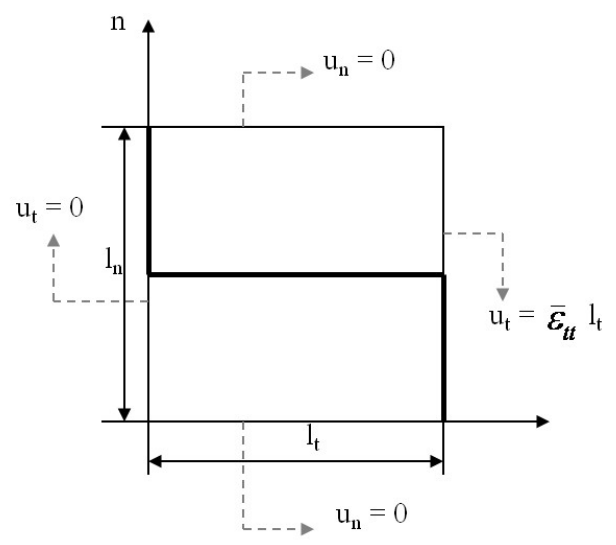

(b)

Figure 7: Boundary and symmetry conditions for the considered quarter cell.

\subsection{Assessment of linearization schemes: the classical secant procedure and its improved variants}

It is worth noting that a nonlinear mean-field homogenization approach relies on two steps: the linearization and the linear homogenization. The first step consists to apply one of the numerous available linearization schemes in order to linearize the nonlinear behaviour and thus to define a linear comparison composite (LCC). For secant linearization schemes, the original nonlinear problem (3) can then be rewritten in the ensuing form

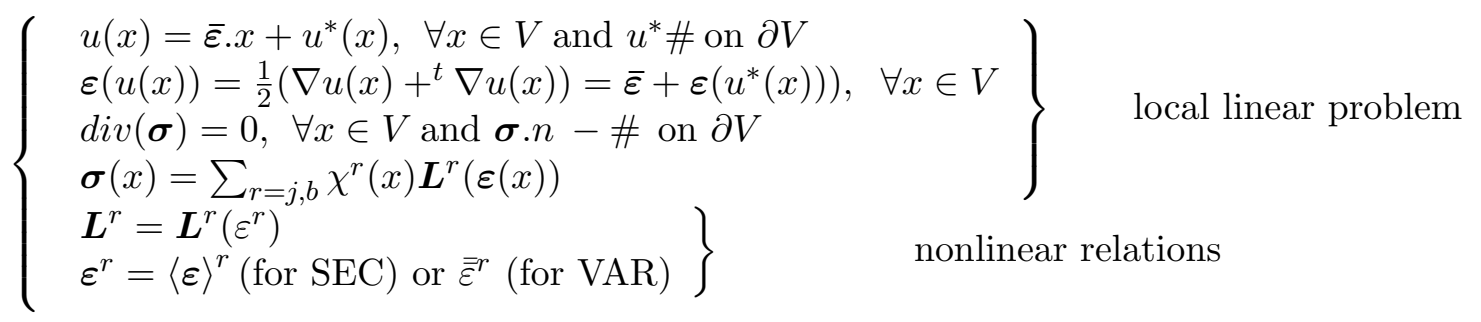

where $\boldsymbol{L}^{r}(\varepsilon)$ are known functions whose exact expressions depend on the chosen linearization scheme (see section (3.2.1)). The procedure followed to solve this system of equations is described below (see section (3.2.2)).

The second step of a nonlinear mean-field homogenization evaluates the effective properties of the LCC defining thus the homogeneous equivalent material (HEM). The effective properties of the HEM are assessed by applying one of the available approximative linear homogenization schemes such as the Hashin-Shtrikman (HS) bounds or the Self-Consistent (SC) model [4]. Frequently, since such approaches induce differences between the microstructure of the nonlinear composite and that of the LCC, it is proposed in this paper - as in [33] - to carry out an "exact" linear homogenization step by considering an LCC with an identical microstructure to that of the nonlinear composite i.e. the periodic unit cell - and using the finite elements method to compute the effective properties of the LCC. Accordingly, the sole effect of the linearization step can be evaluated without any bias related to a change of microstructure or other hypothesis adopted by a classical linear homogenization scheme.

For the linearization step, it is possible to adopt one of the several linearization schemes available in the literature. Nevertheless, since the experimental data in our disposal, related to the dry joint's 
properties are limited, only secant linearization schemes (the classical secant model [3, 15], referred to as by SEC and the modified secant method [31,35,36] noted in the following by VAR) will be treated in this paper. The interest of the VAR method is that it accounts for both the inter and intra-phase strain fluctuations unlike its original version SEC which considers only the inter-phase fluctuations.

In the following, we recall briefly the principle of the tested secant (SEC and VAR) linearization schemes available in the literature. We propose also to test an empirical version of the classical secant method referred to as by $\mathrm{SEC}_{\alpha}$ for which the principle is also explained hereafter.

Note that only the linearization step is explained in this section since the principle of the second step - the periodic linear homogenization procedure - allowing the determination of the effective stiffnesses $\left(\tilde{\boldsymbol{L}}^{S E C}, \tilde{\boldsymbol{L}}^{V A R}\right.$ and $\left.\tilde{\boldsymbol{L}}^{S E C_{\alpha}}\right)$ of the LCC is similar to that followed for the nonlinear periodic unit cell (see section (3.1.2)). The only difference stems from the evaluation of the mortarless joint stiffness tensor $\boldsymbol{L}^{j}=\boldsymbol{L}^{j}\left(\varepsilon^{j}\right)\left(\varepsilon^{j}=\bar{\varepsilon}^{j}\right.$ for SEC and $\overline{\boldsymbol{\varepsilon}}^{j}$ for VAR). The average over phase $r$ of the local stress $\boldsymbol{\sigma}(x)$ in the LCC was computed using finite elements method as it is the case for the nonlinear problem.

\subsubsection{Outline of the tested existing and proposed linearization procedures}

The secant linearization schemes define elastic LCCs unlike others which define thermoelastic ones such as the affine [21] or the second-order [31] methods. Such procedures are not considered in this work for reasons mentioned previously. For elastic LCC, the linearity of the local problem ensures the determination of the local strain field in the LCC from the macroscopic strain $\bar{\varepsilon}$ using the localization relation:

$$
\varepsilon(x)=\boldsymbol{A}(x): \bar{\varepsilon}
$$

where $\boldsymbol{A}(x)$ is the fourth-order localization tensor. The per-phase average strain deduced from relation (11) reads $\bar{\varepsilon}^{r}=<\varepsilon>^{r}=\boldsymbol{A}^{r}: \bar{\varepsilon}$ where the fourth-order tensor $\boldsymbol{A}^{r}$ denotes the localization tensor of each phase $r$. It is not necessarily symmetric and depends only on the microstructure and the local properties, but not on the overall load.

Classical secant procedure (SEC). For this formulation, the constitutive behaviour per phase $r$ inside the LCC reads: $\boldsymbol{\sigma}(x)=\boldsymbol{L}^{r}: \boldsymbol{\varepsilon}(x)$, where $\boldsymbol{L}^{r}$ is defined as the isotropic tensor of secant moduli evaluated at the reference strain $\varepsilon^{r}$, namely:

$$
\boldsymbol{L}^{r}=3 k_{\text {sec }}^{r}\left(\varepsilon^{r}\right) J+2 \mu_{\text {sec }}^{r}\left(\varepsilon^{r}\right) K,
$$

where $\mu_{s e c}^{r}\left(\varepsilon_{e q}\right)=\frac{\sigma_{e q}\left(\varepsilon_{e q}\right)}{3 \varepsilon_{e q}}$ is the secant shear modulus of the nonlinear constitutive relation of phase $r$. $\varepsilon_{e q}$ and $\sigma_{e q}$ are the von Mises equivalents of the strain and stress tensors defined as usually by $\varepsilon_{e q}=\sqrt{\frac{2}{3} \varepsilon: K: \varepsilon}$ and $\sigma_{e q}=\sqrt{\frac{3}{2} \boldsymbol{\sigma}: K: \boldsymbol{\sigma}}$. The bulk modulus $k^{r}$ is given by: $k_{s e c}^{r}\left(\varepsilon_{m}\right)=\frac{\sigma_{m}\left(\varepsilon_{m}\right)}{3 \varepsilon_{m}}$ where $\sigma_{m}=\frac{1}{3} \boldsymbol{i}: \boldsymbol{\sigma}$ and $\varepsilon_{m}=\frac{1}{3} \boldsymbol{i}: \boldsymbol{\varepsilon}$ are the spherical parts of the stress and strain tensors, respectively. $\varepsilon_{m}^{r}=\bar{\varepsilon}_{m}^{r}=\frac{1}{3} \boldsymbol{i}:<\varepsilon>^{r}$ is the spherical part of the average strain field in phase $r$. The notation $<C>^{r}=\frac{1}{V^{r}} \int_{V^{r}} C(x) d x$ denotes the mean value of the tensor $C$ over phase $r$ which occupies the volume $V^{r}$. The fourth-order tensors $\boldsymbol{K}=\boldsymbol{I}-\boldsymbol{J}$ and $\boldsymbol{J}=\frac{1}{3} \boldsymbol{i} \otimes \boldsymbol{i}$ are the usual projectors on the subspaces of purely spherical or deviatoric second-order tensors. The tensors $\boldsymbol{i}$ and $\boldsymbol{I}$ are second and fourth-order symmetric identity tensors. According to the SEC method, the reference strain is defined as the equivalent per-phase average of the strain in the LCC: $\varepsilon_{e q}^{r}=\bar{\varepsilon}_{e q}^{r}=<\varepsilon>_{e q}^{r}$ for the deviatoric part of the nonlinear behaviour and as the hydrostatic part $\bar{\varepsilon}_{m}^{r}$ of the per-phase average strain field in phase $r$ for its spherical part. 
Modified secant extension (VAR). This formulation coincides with the variationnal approach of Ponte Castañeda [31, 35, 36]. In the LCC, the constitutive behaviour per phase is identical to that defined by the SEC method but the reference strain $\varepsilon^{r}$ is set equal to the scalar second-order moment of the strain in phase $r$ in the LCC, namely: $\varepsilon_{e q}^{r}=\overline{\bar{\varepsilon}}_{e q}^{r}=\sqrt{\left\langle\varepsilon_{e q}^{2}\right\rangle^{r}}$ for the deviatoric part and $\varepsilon_{m}^{r}=\bar{\varepsilon}_{m}^{r}=\sqrt{\left\langle\varepsilon_{m}^{2}\right\rangle^{r}}$ for the hydrostatic part.

Improved "empirical" secant procedure $\left(\boldsymbol{S E C} \boldsymbol{C}_{\alpha}\right)$. This formulation is an empirical variant derived from the classical secant scheme. It is proposed in the current work in order to improve the overall predictions of SEC. Its principle is similar to that of some variants of the tangent and classical secant schemes $[24,23]$ based on the introduction of a multiplicative coefficient or a tuning parameter in the phases/matrix interaction law allowing the improvement of the self-consistent results for viscoplastic polycristalline metals. Moreover, this tuning parameter is fitted to finite element results available in the literature.

The proposed formulation $\mathrm{SEC}_{\alpha}$ relies then on the linearization around the reference strain $\alpha \bar{\varepsilon}^{r}$ as a replacement of the per-phase average strain $\bar{\varepsilon}^{r}$ adopted by the SEC scheme. The scalar $\alpha$ has to be adjusted so as the overall prediction of $\mathrm{SEC}_{\alpha}$ fits the reference global response. A computational inverse procedure could provide the appropriate value of the scalar $\alpha$. The stiffness isotropic tensor per phase $r$ is evaluated at the reference strain $\alpha \bar{\varepsilon}^{r}$, namely

$$
\boldsymbol{L}^{r}=3 k_{s e c}^{r}\left(\alpha \varepsilon^{r}\right) J+2 \mu_{s e c}^{r}\left(\alpha \varepsilon^{r}\right) K,
$$

where $\mu_{s e c}^{r}\left(\alpha \varepsilon_{e q}\right)=\frac{\sigma_{e q}\left(\alpha \bar{\varepsilon}_{e q}\right)}{3 \varepsilon_{e q}}$ and $k^{r}\left(\alpha \varepsilon_{m}\right)=\frac{\sigma_{m}\left(\alpha \bar{\varepsilon}_{m}\right)}{3 \varepsilon_{m}}$.

Note that, even though this formulation is empirical, it presents the advantage to be numerically easy to compute. A similar empirical version can also be proposed for the VAR scheme. It is based on the replacement of the second-order reference strain $\overline{\bar{\varepsilon}}^{r}$ by $\alpha \overline{\bar{\varepsilon}}^{r}$ in each phase $r$ in the LCC. Such an approach is not investigated in this work for reason explained in the next section (4). Note that this procedure does not provide bounds neither an effectif potential. Moreover, its main limitation is the necessity to dispose of a reference solution obtained by experiments or FEM or FFT (Fast Fourier Transform) method.

\subsubsection{The linearization step}

Interphase properties in the $\boldsymbol{L} \boldsymbol{C C}$. Since a secant linearization scheme attributes to each phase $r$ in the LCC a secant shear moduli $\mu_{\text {sct }}^{r}$ defined by the equation $[35,5]$

$$
\mu_{s c t}^{r}\left(\varepsilon_{e q}\right)=\frac{\sigma_{e q}\left(\varepsilon_{e q}\right)}{3 \varepsilon_{e q}}
$$

where the von Mises stress (respectively strain) measures the deviatoric part of the stress (respec. strain) tensor as done in $[14,31,33]$, it is useful to define the interphase's behaviour in terms of the " $\sigma_{e q}-\varepsilon_{e q}$ " evolution as shown in Figure (8) provided by the experimental data. According to the definition (14), the secant shear modulus of the interphase in the LCC defined by a secant linearization scheme reads

$$
\mu^{j}\left(\varepsilon_{e q}\right)=\mu_{e}^{j}+\mu_{1} \varepsilon_{e q}^{m_{1}}
$$

where the scalars $\mu_{e}^{j}$ and $\mu_{1}(\mathrm{MPa})$ and the exponent $m_{1}$ are given in Table (4). Note that, in this study, there is no use of the von Mises plasticity criterion since the deviatoric part of the dry joint's behaviour is assumed to be nonlinear elastic following a power-law type relation. The constant $\mu_{e}^{j}$ 
can be considered as the elastic shear modulus of the dry joint since it is provided by the linear part (see Figure (8)-a) of the " $\sigma_{e q}-\varepsilon_{e q}$ " evolution (i.e. $\mu_{e}^{j}=\frac{\sigma_{e q}\left(\varepsilon_{e q}\right)}{3 \varepsilon_{e q}}$ for $\varepsilon_{e q} \leq 0.012$ ). It is worth noting

\begin{tabular}{ccc}
\hline$\mu_{e}^{j}$ & $\mu_{1}$ & $m_{1}$ \\
\hline 0.208 & $10^{7}$ & 4.05 \\
\hline
\end{tabular}

Table 4: Parameters of the evolution of the dry joint's secant shear modulus versus the local equivalent strain.

\section{(a)}

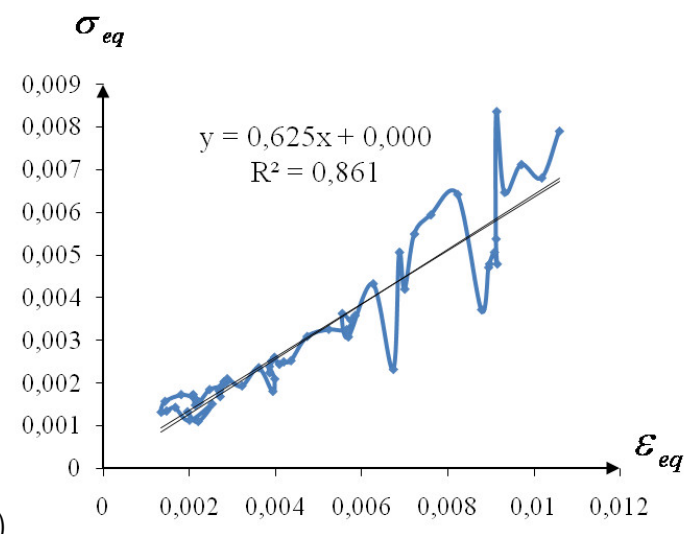

(b)

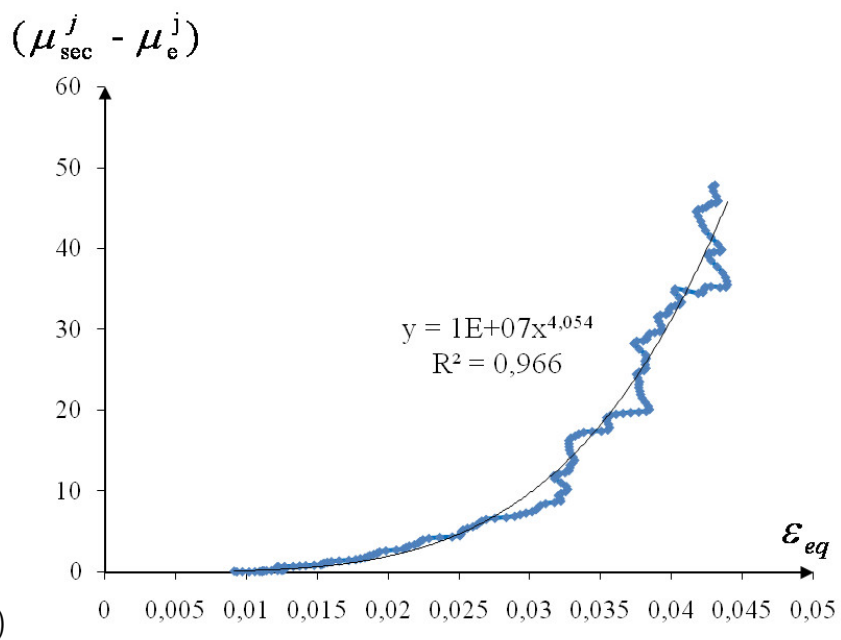

Figure 8: Evolutions of the experimental data: the linear part of the MaC mortarless joint's " $\sigma_{e q}-\varepsilon_{e q}$ " relation (a) and " $\left(\mu_{s e c}^{j}-\mu_{e}^{j}\right)$ " evolution (b) functions of the local equivalent local strain $\varepsilon_{e q}$.

that a polynomial approximation of the shear modulus evolution (15) was avoided as it could lead to aberrant (negative) values for $\mu^{j}$ for some ranges of the local equivalent strain. An exponential approximation was also avoided since such function overestimates $\mu^{j}$ with the increase of the local equivalent strain.

For this step, we choose to not linearize the spherical part of the joint's behaviour but to use the "exact" expression of the parameter $\nu^{j}$ as function of the spherical part $\operatorname{tr}(\varepsilon)$ of the strain field in the joint. It reads

$$
\begin{aligned}
& \nu^{j}(\operatorname{tr}(\varepsilon))=b_{2}(\operatorname{tr}(\varepsilon))^{2}+b_{1}(\operatorname{tr}(\varepsilon))+b_{0} \\
& \begin{array}{ccc}
\hline b_{2} & b_{1} & b_{0} \\
\hline 33.23 & -3.46 & 0.127 \\
\hline
\end{array}
\end{aligned}
$$

Table 5: Parameters used to approximate the MaC dry joint's parameter $\nu^{j}=-\frac{\left\langle\varepsilon_{t t}\right\rangle^{j}}{\left\langle\varepsilon_{n n}\right\rangle^{j}}$ as function of the spherical part of the strain field in the joint.

where the scalars $b_{i}(i=1,3)$ are provided in table $(5)$ and $\operatorname{tr}(\varepsilon)=\boldsymbol{i}: \boldsymbol{\varepsilon}$.

The secant Young's modulus of the interphase can then be deduced as follows $E_{s e c}^{j}=2 \mu^{j}\left(1+\nu^{j}\right)$. Its bulk modulus reads $k^{j}=\frac{E^{j}}{3\left(1-2 \nu^{j}\right)}$. In the LCC, the MaC interphase is then assumed to be an isotropic linear elastic phase characterized by the secant Young's modulus $E_{\text {sec }}^{j}$ and the "exact" joint's parameter $\nu^{j}$ (see formulae (16)). Recall that, the term "exact" is let between quotation marks since it is related to the accuracy of the approximative function used to fit the fluctuant evolution of the parameter $\nu^{j}$ as a function of the spherical part of the local strain. 
For the interphase, it was also possible to linearize the (convex power-law) spherical part of the $\mathrm{MaC}$ joint's behaviour by evaluating the joint's secant bulk's modulus as follows: $k_{s e c}^{j}=\frac{\sigma_{m}\left(\varepsilon_{m}\right)}{3 \varepsilon_{m}}$ and therefore to deduce the following Poisson's ratio $\nu^{j}=\frac{3 k_{s e c}^{j}-2 \mu_{s e c}^{j}}{2\left(3 k_{s e c}^{j}+\mu_{s e c}^{j}\right)}$. Nevertheless, the latter secant bulk's modulus $k_{s e c}^{j}$ risks to lead to aberrant (negative) values for the Poisson's ratio if the adopted (or chosen) function fitting the " $\sigma_{m}-\varepsilon_{m}$ " evolution provided by the DIC method is not so accurate.

Resolution of the nonlinear problem (equation (10)). To define the LCC for each loading step, it is needed to assess the reference strain $\varepsilon^{j}$ for the SEC and VAR procedures. Since there is no experiments carried out on the periodic mortarless masonry cell using the DIC method as it is the case for the laminate elementary structure (see section (2)), we do not have experimental data allowing the deduction of the reference strains $\varepsilon^{j}$ for the mortarless linings. Accordingly, we propose to use an iterative method (the fixed-point for example) in order to resolve the nonlinear set of equations (10). For this nonlinear system, it is recalled that $\boldsymbol{L}^{r}(\varepsilon)$ are known functions whose exact expressions depend on the chosen linearization procedure. Moreover, to ensure numerical accuracy in these investigations, the convergence criterion adopted for the iterative fixed-point method in this work was set equal to $10^{-6}\left(\frac{p_{1}^{r}+p_{0}^{r}}{2}\right)$, where $p_{1}^{r}$ denotes the new evaluation of the reference strain $\varepsilon^{r}$ and $p_{0}^{r}$ is its initial value in each phase $r$. More details about this iterative method are given in [33].

\section{Results and discussion}

This section provides an insight into the influence of the secant linearization procedures on the global and local behaviour of $\mathrm{MaC}$ regular mortarless masonry. To this aim, we consider a periodic cell made of bricks of dimensions $100 \times 50 \mathrm{~mm}^{2}$ and mortarless joint of $0.104 \mathrm{~mm}$ thickness. This cell is descretized through a mesh relying into 50x25, 4x50 and 2x25 4 nodes quadrilateral finite elements inside the brick, the bed and head joints in the quarter cell, respectively. The choice of such discretization instead of more refined mesh with 8 nodes quadrilateral finite elements was motivated by the fact that the former allows the fixed point to converge faster and due to negligible differences between results provided by both meshes. For the simulated results, it is noted that the computations are run until $\bar{\varepsilon}_{n n}=2 \times 10^{-5}\left(\bar{\varepsilon}_{t t}=1.75 \times 10^{-5}\right)$ for unit cell under compression along $\boldsymbol{n}$ (along $\boldsymbol{t}$ ).

\subsection{Effective properties and reference strains}

Evolutions of the computed effective stiffnesses $\left(\tilde{L}_{n n n n}, \tilde{L}_{t t t t}(\mathrm{MPa})\right)$ and Poisson's ratios $\left(\tilde{\nu}_{n t}\right.$ and $\left.\tilde{\nu}_{t n}\right)$ with respect to the imposed macroscopic strain are depicted on Figure (9).

For the mortarless periodic cell submitted to compression along $\boldsymbol{n}$, the secant estimates (see Figure (9)-a and b) reproduce qualitatively well the evolutions of the reference solutions. Moreover the VAR method provides good estimates for the effective stiffness $\tilde{L}_{n n n n}$ and Poisson's ratio $\tilde{\nu}_{t n}$ of the $\mathrm{MaC}$ mortarless masonry. Unlike for usual viscoplastic (concave) power-law composites, the classical secant model leads to too soft overall estimates for the mortarless masonry. The $\mathrm{SEC}_{\alpha_{n}}$ empirical model where the scalar $\alpha_{n}$ is found to be set to 1.3 improves the classical secant procedure overall estimates. Note that $\alpha_{n}$ is superior to 1 . This amplification of the reference strain $\bar{\varepsilon}_{e q}^{j}$ for the classical secant model allows then the definition of an improved LCC more relevant than that defined by the SEC scheme. The computations of the reference strains $\bar{\varepsilon}_{e q}^{j}, \bar{\varepsilon}_{e q}^{j}$ and $\alpha_{n} \bar{\varepsilon}_{e q}^{j}$ for the 

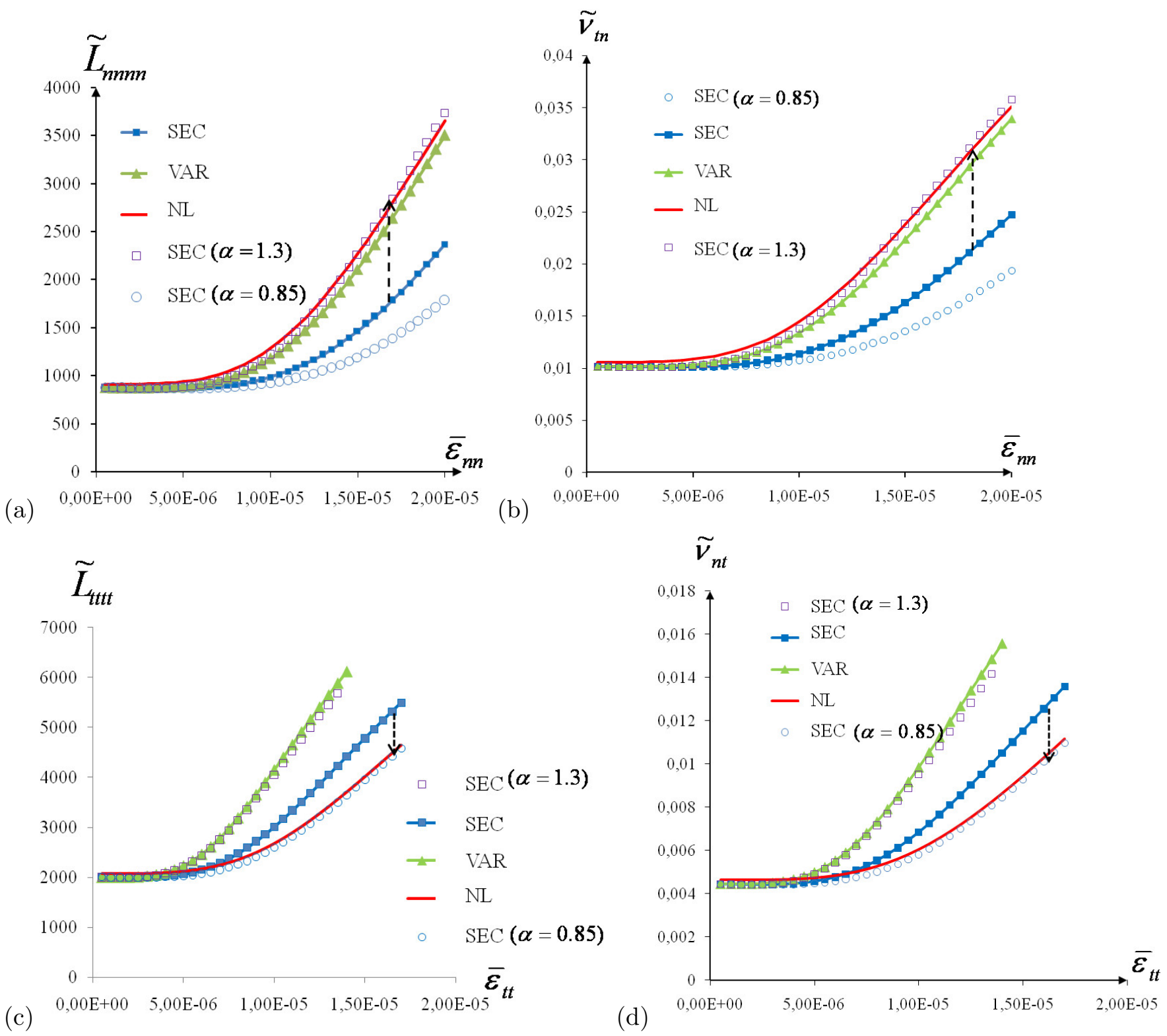

Figure 9: Periodic mortarless masonry cell under compression along $\boldsymbol{n}$ (a-b) or compression along $\boldsymbol{t}$ (c-d): effective mechanical properties versus the macroscopic strain.

SEC, VAR and $\mathrm{SEC}_{\alpha_{n}}$ schemes as illustrated on Figure (10)-a show that the second-order moment of the strain field $\bar{\varepsilon}_{e q}^{j}$ in the dry joint is higher than its first-moment $\bar{\varepsilon}_{e q}^{j}$. This proves the fact that the overall classical secant estimates are softer than those provided by VAR due to the convex trend of the deviatoric part " $\sigma_{e q}-\varepsilon_{e q}$ " of the MaC mortarless joint's behaviour. This justifies also the recourse to a scalar $\alpha$ superior to 1 to obtain stiffer estimate than that provided by SEC for the mortarless masonry. Note that the reference strain $\alpha_{n} \bar{\varepsilon}_{e q}^{j}$ almost coincides with the second-order moment of the strain field $\bar{\varepsilon}_{e q}^{j}$. This argues the quasi-equality between the overall predictions of $\mathrm{SEC}_{\alpha_{n}}$ and VAR. Note that, even though the VAR model is a sophisticated model accounting for both the inter and intraphase strain field fluctuations, the empirical model $\mathrm{SEC}_{\alpha}$ accounting only for the interphase field fluctuations could be a satisfactory alternative for the VAR scheme as it is 
easier to implement and needs less theoretical investigations and numerical expenses. It requires however the implementation of an automatized inverse identification procedure not yet done in this work.

For computations carried out under compression along $\boldsymbol{t}$ (Fig. (9)-c and -d), it is observed that the secant (SEC and VAR) schemes (highly) overestimate the overall reference response. The $\mathrm{SEC}_{\alpha_{t}}$ estimates, with a scalar $\alpha_{t}=0.85$ less than 1 , softens the SEC estimates. Indeed as shown on Figure (10)-b, the reference strain $\alpha_{t} \bar{\varepsilon}_{e q}^{r}$ is softer than the second moment $\overline{\bar{\varepsilon}}_{e q}^{r}$ and obviously than the first moment $\bar{\varepsilon}_{e q}^{r}$ with $\alpha_{t} \bar{\varepsilon}_{e q}^{r} \leq \bar{\varepsilon}_{e q}^{r} \leq \bar{\varepsilon}_{e q}^{r}$. Accordingly and due to the convex qualitative trend of the " $\sigma_{e q}-\varepsilon_{e q}$ " curve for the mortarless MaC joint, the scheme $\mathrm{SEC}_{\alpha_{t}}$ leads to better global estimate than those provided by VAR and SEC. The inequality $\bar{\varepsilon}_{e q}^{r}>\bar{\varepsilon}_{e q}^{r}$ justifies also that VAR overall estimate is stiffer than that provided by SEC in the current study unlike for usual results obtained for usual viscoplastic (concave) power-law composites.

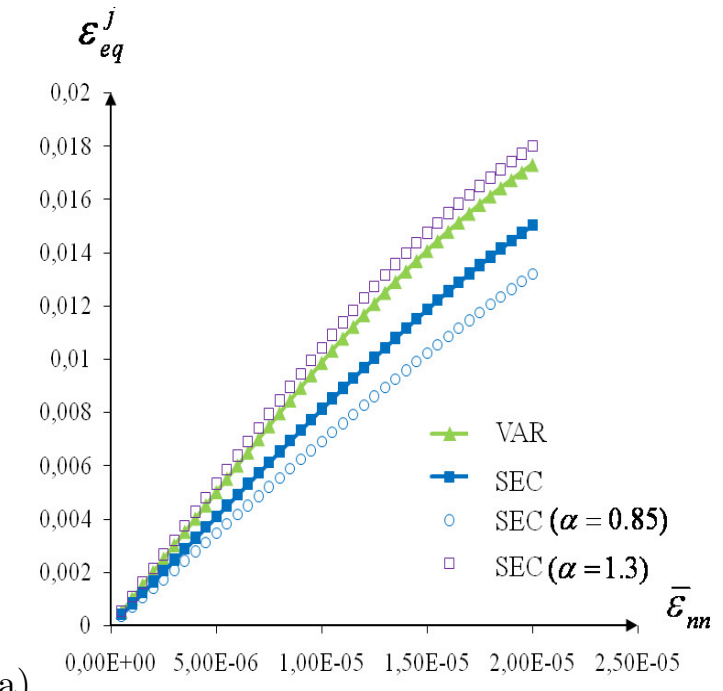

(a)

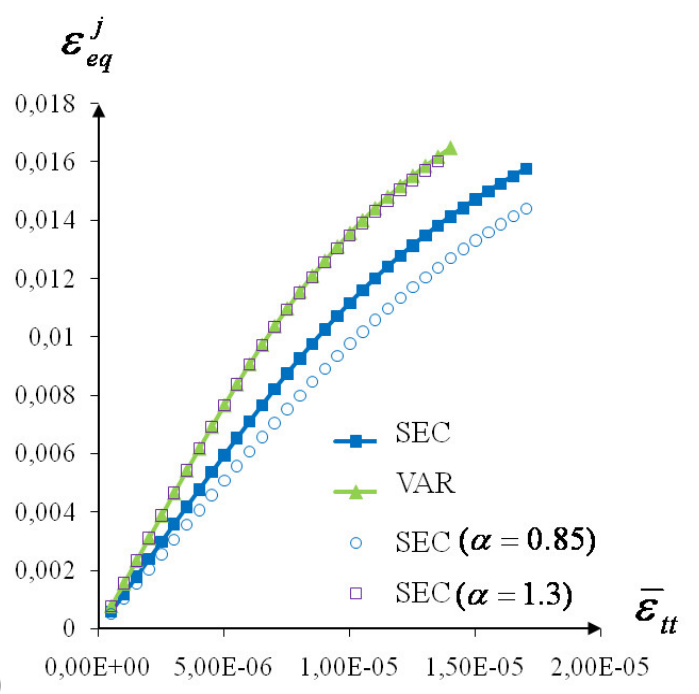

(b)

Figure 10: Evolutions of the reference strains $\varepsilon_{e q}^{j}\left(\bar{\varepsilon}_{e q}^{r}(\mathrm{SEC}), \bar{\varepsilon}_{e q}^{r}(\mathrm{VAR}), \alpha_{t} \bar{\varepsilon}_{e q}^{r}\left(\mathrm{SEC}_{\alpha}\right)\right)$ for the deviatoric part of the $\mathrm{MaC}$ mortarless joint behaviour versus the macroscopic strain for a mortarless periodic masonry cell under compression along $\boldsymbol{n}(\mathrm{a})$ and $\boldsymbol{t}(\mathrm{b})$.

The different general trends observed for the SEC and VAR predictions at the global scale for mortarless masonry under compression along $\boldsymbol{n}$ and that along $\boldsymbol{t}$ can be justified by the set of hypothesis adopted in this study. Indeed, for compression along $\boldsymbol{t}$, the dry joint was assumed to behave as a joint submitted to compression along $\boldsymbol{n}$. Moreover the strain field components $\varepsilon_{t t}$ and $\varepsilon_{z z}$ were assumed to be equal which is not necessarily true. The third hypothesis was related to the plane stress assumption for the nonlinear problem and the linear problems associated to the LCC defined by the secant schemes. Accordingly the overall trends observed for a unit mortarless under compression along $\boldsymbol{n}$ should be more rigorous. Those obtained for the mortarless unit cell under compression along $\boldsymbol{t}$ merit to be checked or confirmed by the investigation of the real dry joint's behaviour under compression along $\boldsymbol{t}$ investigated by means of DIC or other experimental appropriate technique. Such idea is left for future work. 


\subsection{Local fields}

It is expected from this study to argue the results obtained at the global scale and to assess the relevance of the secant schemes (SEC, VAR and $\mathrm{SEC}_{\alpha}$ ) at the local scale.

The deformed mortarless unit cell (in blue color) under compression along $\boldsymbol{n}$ and $\boldsymbol{t}$ are depicted respectively on Figure (11)-a and (11)-b.

The maps illustrating the spatial distributions of the local stress (local strain) fields for the reference solution and secant estimates are reported on Figures (13) and (15) (Figures (12) and (14)). It is noted that the maps predicted by the micromechanical models are plotted according to the scales of the FE fields maps. Nevertheless, the real scales of the strain and stress fields provided by the secant models are illustrated in this paper in order to show the upper and lower values of these fields. Moreover, only the map of reference stress or strain field will be presented if the secant linearization schemes predict qualitatively well the reference local field. Scales of variation of stress or strain field provided by the secant schemes (b, c, d) are also reported without their associated map since their qualitative trend is similar to that of the reference map solution (a).

Note that only the upper brick moves along the $\boldsymbol{t}$ direction due to the presence of the joint with mechanical properties very soft compared to those of the MaC bricks.

(a)

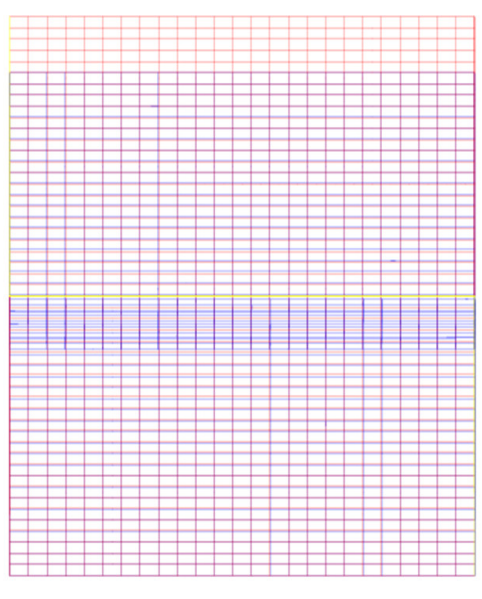

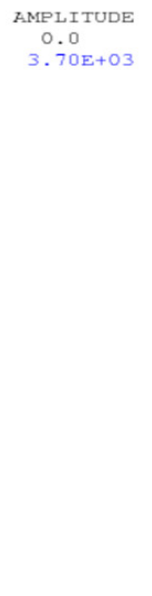

(b)

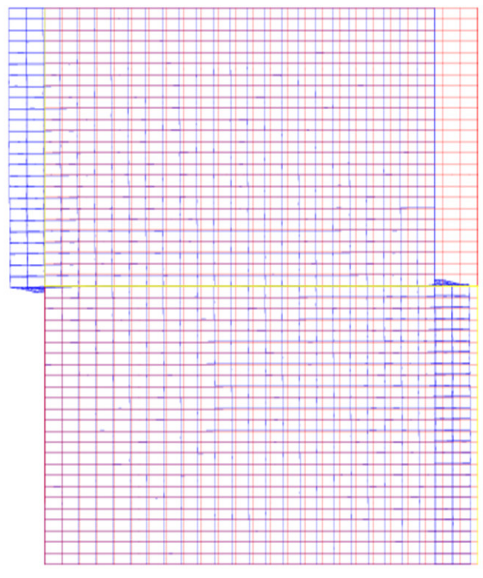

Figure 11: Periodic mortarless masonry cell under compression along $\boldsymbol{n}$ (a) and $\boldsymbol{t}$ (b) $\left(\bar{\varepsilon}_{j j}=1.35 \times 10^{-5}\right)$

Figures (12) and (14) show that the secant models reproduce qualitatively well the distribution maps of the local equivalent strain $\varepsilon_{e q}(x)$ of the NL solution. Moreover, they predict well the zones of strong localization of $\varepsilon_{e q}(x)$ located at the head dry joints (bed dry joints) for periodic mortarless cell submitted to a compression along $\boldsymbol{t}$ (along $\boldsymbol{n}$ ). Quantitatively, for periodic cell under compression along $\boldsymbol{t}$, it is depicted on Fig. (14) that the SEC scheme and especially the VAR model underestimate the strain field $\varepsilon_{e q}(x)$ in opposition to the $\operatorname{SEC}_{\alpha_{t}}\left(\alpha_{t}=0.85\right)$ scheme which estimates well the reference solution in the head mortarless joints. For all models (NL and secant schemes), note that $\varepsilon_{e q}(x)$ localizes also in the bed joints but quantitatively, the intensity of $\varepsilon_{e q}(x)$ is less than that observed for this field inside head joints.

For periodic cell under compression along $\boldsymbol{n}$, it is observed in Fig. (12) that almost all models (SEC, $\mathrm{VAR}$ and $\left.\mathrm{SEC}_{\alpha_{n}}\right)$ estimate well the strain field $\varepsilon_{e q}(x)$ even though $\mathrm{VAR}$ and $\mathrm{SEC}_{\alpha_{n}}\left(\alpha_{n}=1.3\right)$ slightly underestimate this field at the bed joints which represent the localization regions of $\varepsilon_{e q}(x)$ 


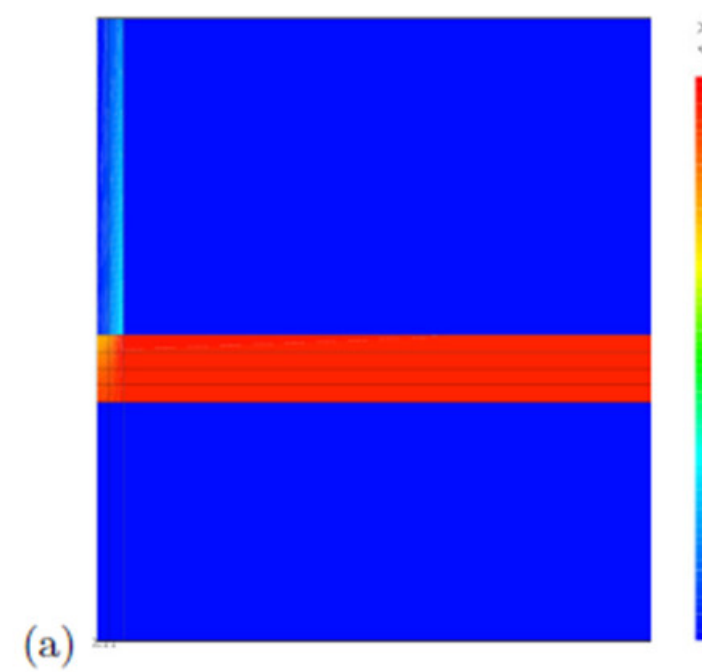

(a)

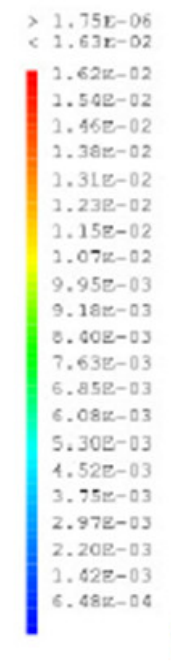

(b)

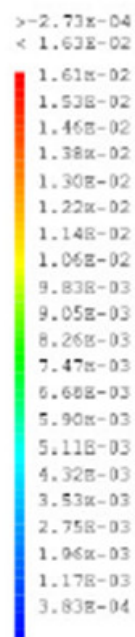

(c)

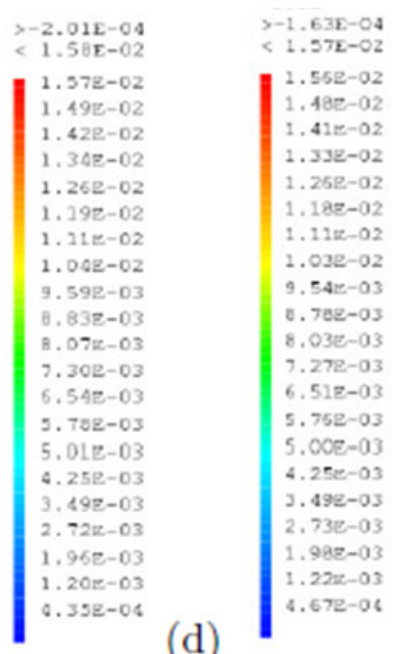

(d)

Figure 12: Periodic masonry cell under compression along $\boldsymbol{n}\left(\bar{\varepsilon}_{n n}=1.35 \times 10^{-5}\right)$ : maps of the equivalent strain $\varepsilon_{e q}(x)$ in the left corner of the nonlinear cell (a) and LCCs provided by the SEC (b), VAR (c) and $\mathrm{SEC}_{\alpha}$ (d) linearization schemes.

(a)

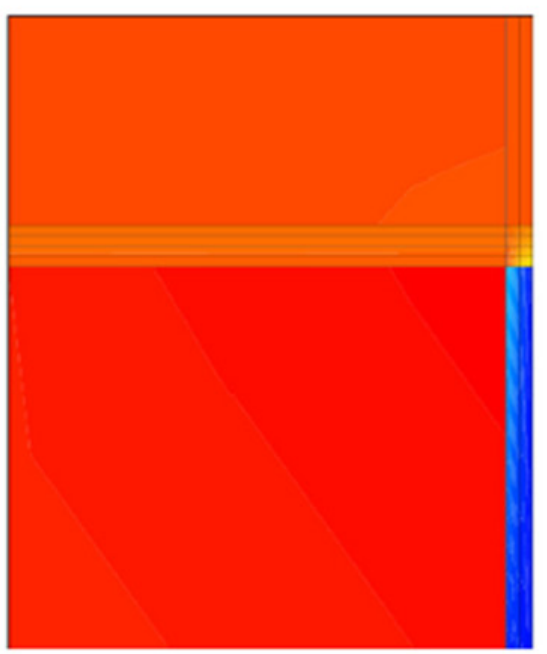

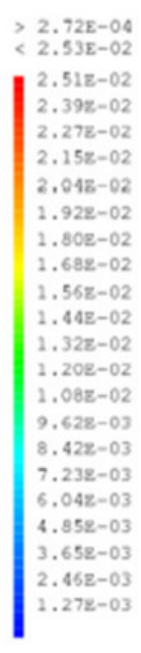

(b)

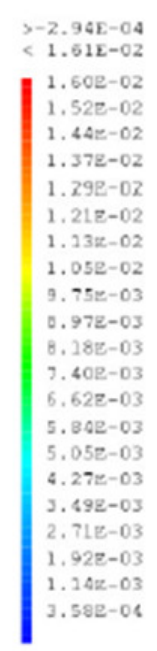

(c)

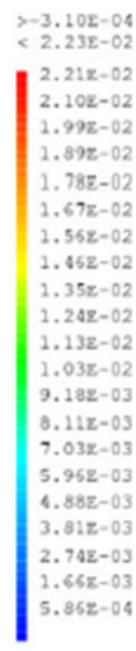

(d)

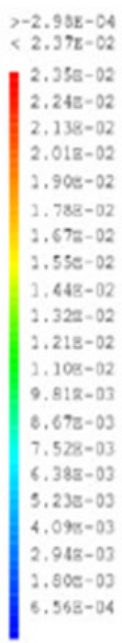

Figure 13: Periodic masonry cell under compression along $\boldsymbol{n}\left(\bar{\varepsilon}_{n n}=1.35 \times 10^{-5}\right)$ : maps of the local equivalent stress $\sigma_{e q}(x)$ in the mortarless bed joint in the nonlinear cell (a) and LCCs provided by the SEC (b), VAR (c) and SEC $\alpha$ (d) linearization schemes. 
under this loading.
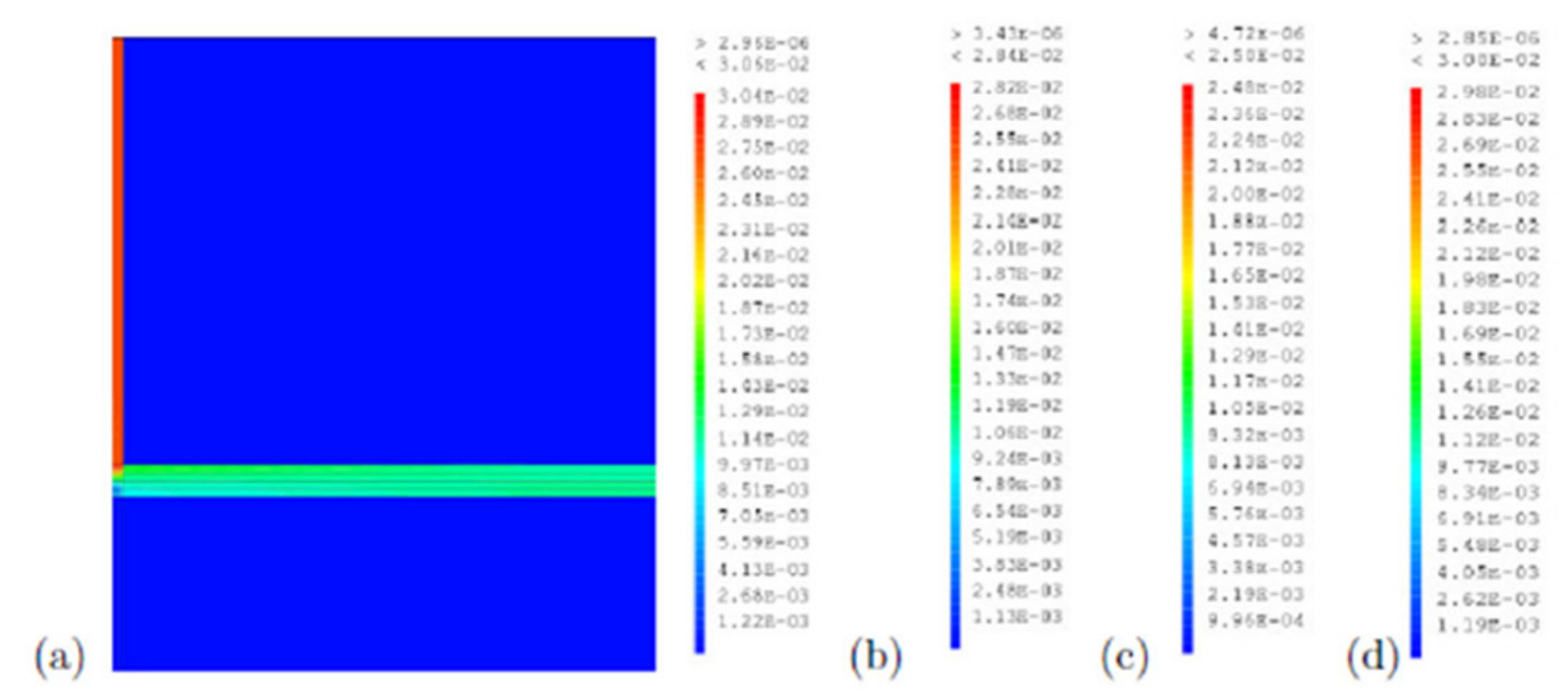

Figure 14: Periodic masonry cell under compression along $\boldsymbol{t}\left(\bar{\varepsilon}_{t t}=1.35 \times 10^{-5}\right)$ : maps of the equivalent strain $\varepsilon_{e q}(x)$ in the left corner of the nonlinear cell (a) and LCCs provided by the SEC (b), VAR (c) and SEC S $_{\alpha}$ (d) linearization schemes.

For maps of the local equivalent stress $\sigma_{e q}(x)$ in the periodic cell submitted to compression along $\boldsymbol{n}$, it is observed on Fig. (13) that all models reproduce qualitatively well the reference solution and especially the zones of strong concentration of the local equivalent stress - inside the bed joints and more strongly in the bricks-. The head joints are almost free from stress. Quantitatively, while $\mathrm{SEC}_{\alpha_{n}}$ and VAR procedures slightly underestimate the reference map, the SEC scheme gives too soft predictions for $\sigma_{e q}(x)$ in zones of strong localization. This observation can justify that obtained at the global scale (too soft overall estimate for SEC and good predictions for VAR and $\mathrm{SEC}_{\alpha_{n}}$ ). For mortarless unit cell under compression along $\boldsymbol{t}$, the secant models reproduce qualitatively well the stress local field distribution even though they predict more enlarged zones of concentration of $\sigma_{e q}(x)$ around the bed joint - but not inside bed joints which are free from stress - and particularly at the right (left) corner of the higher (lower) brick compared to that observed on the reference map (NL). Quantitatively, the SEC model predicts slightly stiffer estimates for the $\sigma_{e q}(x)$ field in these regions of strong concentration. The VAR scheme clearly highly overestimates the reference solution. This local result argues the too stiff evaluations provided by VAR at the global scale. The local predictions of $\mathrm{SEC}_{\alpha_{t}}$ are in good agreement with NL and lead then to better overall estimates.

\section{Conclusion and perspectives}

In this paper, the dry joint was assumed to be an interphase perfectly bonded with MaC bricks. Accordingly it was possible to apply mean-field homogenization theories to the mortarless masonry. A convex power-law behaviour was identified for the dry joint using the DIC method for an elementary mortarless specimen under compression orthogonal to the plane of the joint. A rigorous assessment of the existing secant linearization schemes for a mortarless periodic masonry 
(a)

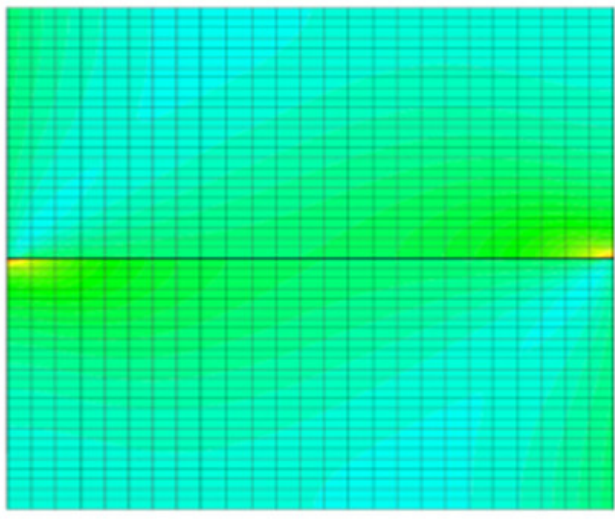

(b)

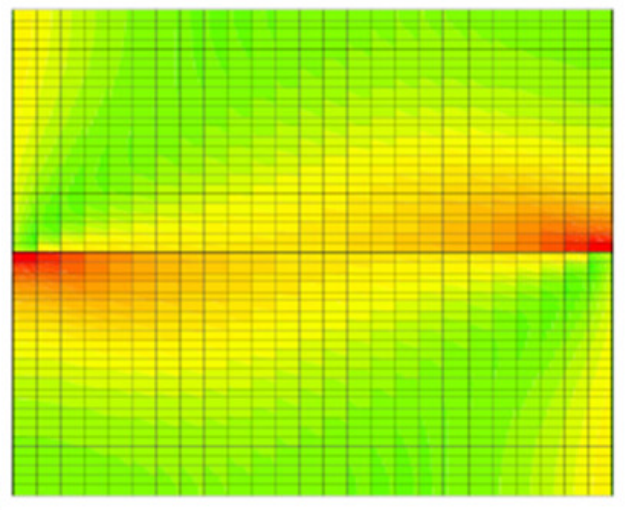

(c)
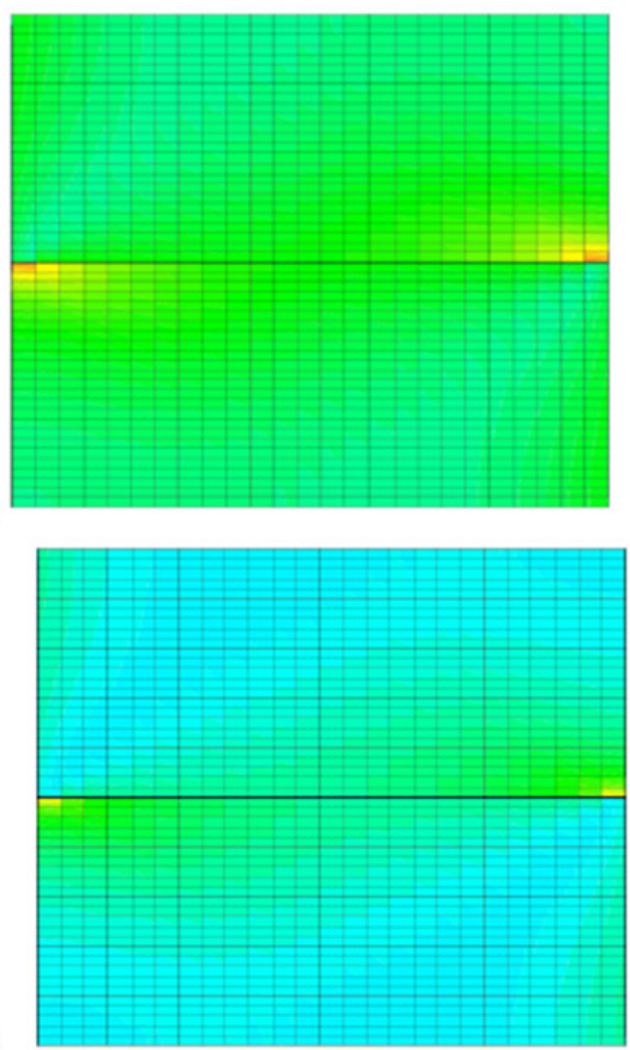
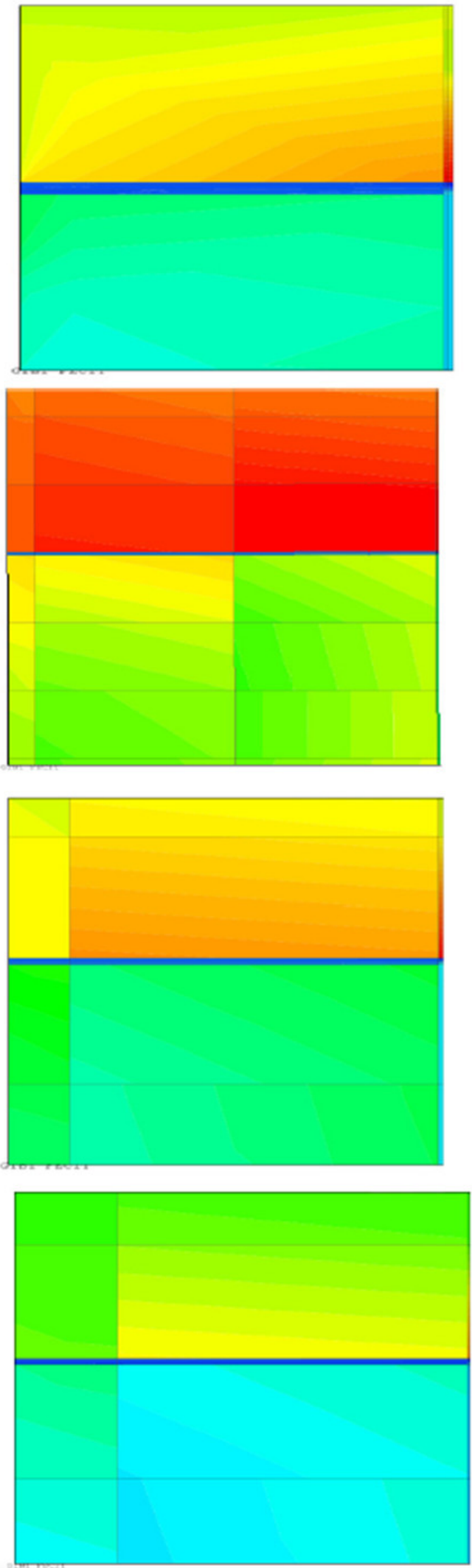

$\geq 4.275-03$

0.21

0.20

$0.505-02$
$0.355-02$

0. $395-02$

3. $69 \mathrm{k}-02$

a. $30 \mathrm{k}-02$

7. $385-02$

5. $885-02$

6.

S. 37 Th-02

3.37n-02

4. $35 \mathrm{~b}-02$

3.85र-62

$2.065-02$

2. $35=02$

. 65 sh-0a

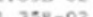

0. 465-03

$6.31 x-03$
$4+-45-01$

0.15
0.15
0.34

0.15

0.14

0.13

0.13
0.12
0.12

0.12

0.10

$9.65 v-02$

$9.65 \mathrm{E}-02$
$8.96 \mathrm{z}-02$
$8.268-02$

$8.260-03$

$8.205-02$
$7.992-02$

c. $052-02$

6.15e-02

5. $40 \mathrm{ve}-02$

1. $705-02$

$4.038-02$

$3.335-02$

$2.63 e-0$ ?

$1.92 E-0$ :

2. 22 - 02

$4 \cdot 345-03$

(1.13z=-

0.11
0.11
0.10

0.10

$9.678-02$

9.15z-02

8.638-02

9. $11 \%-02$

7. $598-02$

$7.072-02$
$6.558-02$

5. $04 \mathrm{E}-02$

5. $528-02$

5. $00 \mathrm{k}-02$

4. $48 z-02$

$3.96 z-02$
$3,44 z-02$
$2.928-02$

$2.928-02$

2. $40 \mathrm{E}-02$

1. $898-02$

1. $37 \mathrm{k}-02$

8. 458-03

$\begin{array}{r}3.43 \mathrm{x}-03 \\ <\quad 9.30 x-02 \\ \hline\end{array}$

9.3LE-02

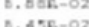

$8.456-02$
0.452
$0.025-02$

$7.99 \mathrm{~g}-02$

7.1 EE-02

c. $735-02$

t. $30 \mathrm{ar}-02$

$5.00 \mathrm{E}-02$

$5.435-02$

$5.005-02$

$4.57 \mathrm{r}-02$

$4.14 \mathrm{E}-02$

$3.715-02$

$3.285-02$

$2.855 .-02$

$2.42 \mathrm{E}-02$

$3.99 \mathrm{E}-02$

$2.506-02$

$1.13 \mathrm{~s}-02$

(d)

$7,025-03$

Figure 15: Periodic masonry cell under compression along $\boldsymbol{t}\left(\bar{\varepsilon}_{t t}=1.35 \times 10^{-5}\right)$ : maps of the local equivalent stress $\sigma_{e q}(x)$ in the mortarless bed joint in the nonlinear cell (a) and LCCs provided by the VAR (b), SEC (c) and $\mathrm{SEC}_{\alpha_{t}}$ (d) linearization schemes. 
by reference to the FE solution demonstrates the superiority of the VAR model compared to the SEC scheme for mortarless unit cell under normal compression. This result confirms again - as it is the case for usual viscoplastic (concave) power-law materials - the relevance of the VAR model since it accounts for both the inter and intraphase strain fluctuations instead of the SEC model which considers only the interphase fluctuations. Unusually, the SEC estimates are softer than the VAR and NL responses. This is due to the convex qualitative trend of the deviatoric part of the dry joint behaviour instead of the usual concave trend of viscoplastic power-law composites. For mortarless unit cell under tangential compression, different trends have been observed. The secant estimates, especially the VAR predictions, have been observed to be (too) stiff. To improve these results, an empirical variant $\mathrm{SEC}_{\alpha}$ of the SEC scheme was proposed. It relies on the adjustment of a scalar $\alpha$ in order to reduce (amplify) the reference strain $\bar{\varepsilon}_{e q}^{r}$ if the SEC overall estimate is stiffer (softer) than the NL solution. The appropriate value of the parameter $\alpha$ leads to global and local estimates in well agreement with the reference solution. Even though the proposed model is not based on theoretical investigations and accounts only for interphase field fluctuations, it could be a satisfactory alternative for the secant schemes (SEC and VAR) if these models lead to too stiff or soft estimates.

The evaluations and comparisons carried out in the current study can be extended to mortarless refractory linings submitted to loading-unloading compressive cycles at room and high temperatures. It can also be carried out under other mechanical tests (shear or bi-axial loading) at various ranges of temperatures. However, it is important to have reliable reference solutions provided, for instance, by experiments based on the DIC method. These perspectives are left for future works. The empirical parametrical model proposed in this paper for the classical secant scheme can also be applied for the VAR model. The relevance of the parametrical models $\mathrm{SEC}_{\alpha}$ and $\mathrm{VAR}_{\alpha}$ can be tested for other materials or composites for which the behaviour of each constituents follows other more general laws. These parametrical models require however a reference solution provided by experiments or FEM or FFT method. A computational inverse procedure could facilitate the determination of the tuning parameter $\alpha$. This approach can also be extended either for other types of brick materials or more generally for conventional mortared masonry at room or high temperatures.

\section{Acknowledgments}

The authors are thankful to FIRE (Federation for International Refractory Research and Education) for the financial support of this work.

\section{References}

[1] Andreev, K., Sinnema S., Rekik, A., Allaoui, S., Blond, E., Gasser, A., 2012. Compressive behaviour of dry joints in refractory ceramic masonry. Construction and Building Materials 34, 402-408.

[2] Alpa, G., Monetto, I., 1998. Dry block assembly continuum modelling for the in-plane analysis of shear walls. Proceeding of the fourth international symposium on computer methods in structural Masonry, Italy, 111-8.

[3] Berveiller, M., Zaoui, A., 1979. An extension of the self-consistent scheme to plastically-flowing polycrystals. J. Mech. Phys. Solids 26, 325-344. 
[4] Bornert, M., 2001. Homogénéisation des milieux aléatoires, in: Bornert M., Bretheau T., Gilormini P. (Eds), Homogénéisation en mécanique des matériaux. Tome 1, Hermes Science, Chapter 5, 133-221.

[5] Bornert, M., Suquet, P., 2001. Propriétés non linéaires des composites: approches par les potentiels, in: Bornert M., Bretheau T., Gilormini P. (Eds), Homogénéisation en mécanique des matériaux. Tome 2, Hermes Science, Chapter 2, 45-90.

[6] Brulin, J., Roulet, F., Rekik, A., Blond, E., Gasser, A., Mc Nally, R., Micollier, M., 2011. Latest evolution in Blast Furnace Hearth thermo-mechanical stress modelling, 4th International Conference on Modelling and Simulation of Metallurgical Processes in Steelmaking, Dusseldorf : France.

[7] http://www-cast3m.cea.fr/

[8] Chaboche, J.L., Kanouté, P., 2003. Sur les approximations "isotrope" et "anisotrope" de l'opérateur tangent pour les méthodes tangentes incrémentale et affine. C. R. Mécanique 331, 857-864.

[9] Di Pasquale, S., 1992. New trends in the analysis of masonry structures. Mechanica, 27, 173-84.

[10] Gasser, A., Spangenberg, J., Blond, E., Rekik, A., Andreev, K., 2011. Comparison of different designs of bottom linings with Dry Joints, UNITECR'11, Kyoto : Japan.

[11] Gasser, A., Terny-Rebeyrotte, K., Boisse, P., 2004. Modelling of joint effects on refractory lining behaviour. J. Mater.: Design Appl. (IMechE) 218, 19-28.

[12] Giambanco, G., Di Gati, L., 1997. A cohesive interface model for the structural mechanics of block masonry. Mechanica Research Communications, 24 (5), 503-512.

[13] Giambanco, G., Rizzo, S., Spallino, R., 2001. Numerical analysis of masonry structures via interface models. Computer Methods in Applied Mechanics of Engineering, 6494-511.

[14] Gilormini, G., Brenner, R., Castelnau, O., 2001. A similarity between the classical and modified secant extensions of the self-consistent model. C. R. Mécanique 329, 523-527.

[15] Hutchinson, J., 1976. Bounds and self-consistent estimates for creep of polycrystalline materials. Proc. Roy. Soc. London A348, 101-127.

[16] Levin, V. M., 1967. Thermal expansion coefficients of heterogeneous materials, Mekh. Tverd. Tela. 2, 83-94.

[17] Lourenço, P.B., 1998. Continuum model for masonry: parameter estimation and validation. ASCE Journal of Structural Engineering, 124 (6), 642-652.

[18] Lourenço, P.B., 1996. Computational strategies for masonry structures. Ph. D. Thesis, The Netherlands: Delft University of Technology.

[19] Lourenço, P.B., Rots, J., 1997. A multi-surface interface model for the analysis of masonry structures. Journal of Engineering Mechanics ASCE 123(7), 660-668. 
[20] Lourenço, P.B., Rots, J., 1993. On the use of macro-models for the analysis of masonry shear walls. Proceeding of the 2nd international symposium on computer methods in structural masonry, 14-26.

[21] Masson, R., Bornert, M., Suquet, P., Zaoui, A., 2000. An affine formulation for the prediction of the effective properties of nonlinear composites and polycrystals. J. Mech. Phys. Solids, 48, 1203-1227.

[22] Marfia, S., Sacco, E., 2005. Numerical procedure for elasto-plastic no-tension model. International Journal of Computational Methods in Engineering Science and Mechanics, 6, 99-187.

[23] Molinari, A., Ahzi, S., Kouddane, R., 1997. On the self-consistent modeling of elastic-plastic behaviour of polycrystals. Mechanics of Materials, 26 , 43-62.

[24] Molinari, A., Toth, L.S., 1994. Tuning a self-consistent visco-plastic model by finite element results, part I: modelling. Acta Metall. Mater., 42 , 2453-2458.

[25] Michel, J.-C., Moulinec, H., Suquet, P., 2001. Composites à microstructure périodique, in: Bornert M., Bretheau T., Gilormini P. (Eds), Homogénéisation en mécanique des matériaux. Tome 1, Hermes Science, Chapter 3, 57-94.

[26] Nguyen, T.M.H., Blond, E., Gasser, A., Prietl, T., 2009. Mechanical homogenisation of masonry wall without mortar. European Journal of Mechanics - A/Solids, Volume 28, Issue 3, $535-544$.

[27] Oh, K., 1994. Development and investigation of failure mechanism of interlocking mortarless block masonry system. Ph. D. Thesis, Drexel University, Philadelphia.

[28] Pegon, P., Pinto, A., Géradin, M., 2001. Numerical modeling of stone-block monumental structures. Computers and Structures, 79, 2165-2181.

[29] Pelissou, C., Lebon, F., 2009. Asymptotic modeling of quasi-brittle interfaces. Computers and Structures, 87, 1216-1223.

[30] Ponte Castañeda, P., 1991. The effective mechanical properties of nonlinear isotropic composites. J. Mech. Phys. Solids 39 (1), 45-71.

[31] Ponte Castañeda, P., 1991. The effective mechanical properties of nonlinear isotropic composites. J. Mech. Phys. Solids 39, 45-71.

[32] Rekik, A., 2006. Une méthodologie pour une évaluation précise des procédures de linéarisation en homogénéisation non linéaire. Ph.D. thesis, Ecole Polytechnique.

[33] Rekik, A., Auslender, F., Bornert, M., Zaoui, A., 2007. Objective evaluation of linearization procedures in nonlinear homogenization: A methodology and some implications on the accuracy of micromechanical schemes. Int. J. Solids and Struct., 44 (10), 3468-3496.

[34] Rekik, A., Lebon, F., 2010. Identification of the representative crack length evolution in a multilevel interface model for quasi-brittle masonry. International Journal of Solids and Structures, 47, 3011-3021. 
[35] Suquet, P., 1995. Overall properties of nonlinear composites: a modified secant moduli theory and its link with Ponte Castañeda's nonlinear variational procedure. C.R. Mécanique 320, 563-571.

[36] Suquet, P., 2001. Nonlinear Composites: Secant methods and variational bounds. Lemaitre Handbook of Materials Behaviour Models, Section 10.3, Academic Press, 968-983.

[37] Senthivel, R., Lourenço, P.B., 2009. Finite element modelling of deformation characteristics of historical stone masonry shear walls. Engineering structures, 31, 1930-1943.

[38] Sutton, M. A., Wolters, W. J., Peters, W. H., Ranson, W. F., McNeill, S. R., 1983. Determination of displacements using an improved digital correlation method. Image and Vision Computing, 1 (3), 133-139.

[39] Thanoon, W. A., Alwathaf, A. H., Noorzaei J., Jaafar, M. S., Abdulkadir, M. R., 2008. Finite element analysis of interlocking mortarless hollow block masonry prism. Computers and Structures, 86, 520-528.

[40] Thanoon, W. A., Alwathaf, A. H., Noorzaei, J., Jaafar, M. S., Abdulkadir, M. R., Nonlinear finite element analysis of grouted and ungrouted hollow interlocking mortarless block masonry system, 2008. Engineering Structures, 30, 1560-1572.

[41] Vacher, P., Dumoulin, S., Arrieux, R., 1999. Determination of the forming limit diagram from local measurement using digital image analysis. International Journal of Forming Processes, 2, 395-408.

[42] Vacher, P., Dumoulin, S., Morestin, F., Mguil-Touchal, S., Bidimensional strain measurement using digital images, 1999. Proceedings of the Institution of Mechanical Engineers, 213, 811817. 